Volume 16, No. 4, Fall 1987

ISSN $0710-4340$

An Extension of PSI Through the

Application of Instructional Systems

Design Technology

Dan O Coldeway

Annabel E. Coldeway

The Value of Supplementing Panel

Software Reviews with

Field Observations

Ronald D. Owston

Herbert H. Wideman

The Integration of Educational

Technology in the University

Diana R. Carl

Tele-Cottages in the Nordic Countries

Henning Albrechtsen

An AMTEC Publication 


$\begin{array}{ll}\text { EDITORIAL BOARD } & \text { Richard F. Schmid } \\ & \text { Concordia University } \\ \text { Jon Baggaley } & \text { Richard A. Schwier } \\ \text { Concordia University } & \text { University of Saskatchewan } \\ \text { Don Beckwith } & \text { Mariela Tovar } \\ \text { Concordia University } & \text { Concordia University } \\ \text { F. Barry Brown } & \text { Jesus Vazquez-Abad } \\ \text { University of Saskatchewan } & \text { Concordia University } \\ \text { Elaine Bruce } & \text { Cynthia B. Weston } \\ \text { Concordia University } & \text { McGill University } \\ \text { Bruce Clark } & \text { Laura R. Winer } \\ \text { University of Calgary } & \text { A PO Quebec } \\ \text { Dan Coldeway } & \text { AMTEC BOARD OF } \\ \text { A thabasca University } & \text { DIRECTORS } \\ \text { George L. Geis } & \text { President } \\ \text { McGill University } & \text { Richard F. Lewis } \\ \text { W. D. Godfrey } & \text { University of Windsor } \\ \text { Softwords } & \text { Past President } \\ \text { William Hanson } & \text { Ed Crisp } \\ \text { Calgary Board of Education } & \text { The University of Western Ontario } \\ \text { William Hillgartner } & \text { President Elect } \\ \text { McGill University } & \text { June R. Landsburg } \\ \text { Denis Hlynka } & \text { Simon Fraser University } \\ \text { University of Manitoba } & \text { Secretary/Treasurer } \\ \text { Robert Jones } & \text { Ron Eyre } \\ \text { Sheridan College of Applied } & \text { The Wellington County Board of } \\ \text { Arts and Technology } & \text { Education } \\ \text { Richard F. Lewis } & \text { Director } \\ \text { University of Windsor } & \text { F. Barry Brown } \\ \text { Hanna Mayer } & \text { University of Saskatchewan } \\ \text { Bank of Montreal Institute } & \text { Director } \\ \text { Tom Rich } & \text { Greg McDonald } \\ \text { Prince Edward Island Department } & \text { Nova Scotia Department of Education } \\ \text { of Education } & \text { Director } \\ \text { Lauran Sandals } & \text { Robert Jones } \\ \text { University of Calgary } & \text { Sheridan College of Applied Arts } \\ & \text { and Technology } \\ & \\ \text { and } & \end{array}$




\section{Canadian Journal of Educational Communication}

\section{Volume 16, Number 4} Fall 1987

\section{Editor}

Robert M. Bernard

\section{Assistant Editors}

Jacques LeCavalier

Steven Shaw

\section{Editorial Assistant}

Lindy Amato

\section{Production Assistant}

Helen de Gourville

\section{Column Editors}

Richard Ellis, From the Media Periodicals Len Proctor, Microware Review Rose Bene, Book Reviews

ISSN $0710 \cdot 4340$

The Canadian Journal of Educational Communication is published quarterly by the Association for Media and Technology in Education in Canada; 500 Victoria Road North; Guelph, Ontario N1 E 6K2; Canada; Attention: Mr. Ron Eyre, Secretary/Treasurer.

Notification of address 'change should be sent to the above. All articles are copyright by AMTEC and may be reproduced for nonprofit use without permission provided credit is given to CJEC. Back issues of CJEC are $\$ 10$ Canadian and may be obtained by contacting the Editor. CJEC is indexed in the Canadian Education Index and ERIC.

Second Class Mail Registration No. 6956

\section{ARTICLES}

An Extension of PSI Through

the Application of Instructional Systems Design Technology Annabel E. Coldeway Dan 0 Coldeway

The Value of Supplementing Panel Software Reviews with Field Observations Ronald D. Owston Herbert $H$. Wideman

The Integration of Educational 309 Technology in the University Diana R. Car/

\section{PROFILE}

Tele-Cottages in the Nordic Countries

Henning Albrechtsen

\section{COLUMNS}

From the Educational Communication and

Technology Periodicals

Book Reviews

Index to Volume 16, 1987

All correspondence should be addressed to:

Dr. Robert M. Bernard, Editor Education Department Concordia University 1455 de Maisonneuve Blvd. W. Montreal, PQ, Canada H3G $1 \mathrm{M} 8$ 


\section{In Future Issues}

PERSPECTIVE

What is the Future of

Educational Technology?

Don Beckwith

Televised University Teaching:

Cost Analysis of a Laboratory

Class

Ruth C. Mackay

E Joyce Carver

The Renfrew Quality Education Project: Teachers' Views after the First Year

Donna Sharon

Computerized Television:

New Developments in Television Production Techniques

Nikos Metallinos

\section{CJEC ORDER FORM}

CJEC is free to members of AMTEC. However, many prefer to order the journal separately, and may do so by completing the form below:

(Name)

(Address)

$\$ 40.00$ (Cdn.) annual subscription

New Subscriber

Renewal

Please send me information about AMTEC and a membership form.

CHANGE OF ADDRESS

Send this form to:

Mr. Ron Eyre

AMTEC

500 Victoria Road North

Guelph, Ontario NHE 6K2

Canada

Printing: McGill Printing Services. 


\title{
An Extension of PSI Through the Application of Instructional Systems Design Technology
}

\section{Annabel E. Coldeway Dan 0 Coldeway}

\begin{abstract}
Keller's Personalized System of Instruction has been an important innovation in higher education. Although the success of PSI is far reaching, it is not without critics. Keller and other PSI advocates report that many PSI failures were due to people not adhering carefully to the PSI principles and components. This paper addressesthis problem from an instructional systems design perspective and the results suggest that modifications to PSI can be done successfully. Moreover, a systematic approach to the design, development and implementation of courses allows the user to meet the important achievement and successgoals of PSI while avoiding the problems that PSI presents in certain contexts.
\end{abstract}

Keller's Personalized System of Instruction (PSI) has received considerable attention, both in practice and research (Keller, 1968; Ruskin, 1976; Kulik, Kulik, \& Cohen, 1979). An analysis of the research indicated that PSI has been effective in improving end of course achievement, retention and transfer of knowledge learned in the course, time to completion of learning objectives, and student satisfaction (Kulik et al., 1979).

PSI is based largely on principles derived from the experimental analysis of behavior. Learning is viewed as behavior generated and maintained by consequences and conditions set by the PSI methodology. The focus is on individual mastery of clearly specified behavioral objectives. The study materials set the occasion for the student to respond and small units of instructional material allow for frequent evaluation of learning. Students receive feedback on their performance, both from the instructional materials and from proctors who serve in an evaluation and student guidance role. Students typically work individually and at their own pace. They also choose the amount of instructional assistance they need, either prior to unit evaluation or as a result of the feedback they receive after completing a unit test.

Keller and many of his associates have strongly advocated strict adherence to his guidelines for PSI courses. Keller has frequently indicated his frustration with what he calls SLI (something like it) approaches to PSI that often fail to follow all the PSI

Annabel E. Coldeway is Associate Professor of Psychology at Concordia College, Edmonton, AB. Dan 0. Coldeway is a Professor with the Centre for Distance Education, Athabasca University. 
guidelines. Frequently such SLI applications report that PSI does not work successfully, causing Keller and others another source of frustration (Keller, 1984). On the other hand, careful variations of PSI have worked extremely well (e.g., Kulik, Jaksa, \& Kulik, 1978). Instructors with a thorough understanding of the principles of behavior and the systematic design of instructional systems can often turn SLI into a very successful course. Coldeway and Spencer (1982) have argued that PSI may be the basic paradigm for the design of many forms of individualized instruction if the rules underlying PSI are well understood and followed appropriately.

Although there is no question that PSI can be used in a variety of settings and in a variety of content areas (Ruskin, 1976), situations also arise where strict adherence to the PSI methodology is impossible or impractical Instead of dismissing the strengths that underlie PSI, instructors in such situations should consider modifying PSI methodology rather than retreating to conventional instructional approaches that may not be the solution to the problem.

This paper describes a behavioral approach to the design and delivery of a course in introductory psychology. The course clearly represents an approach to teaching that has a focus on the individual learner and attempts to capitalize on the effective use of behavior analysis and instructional systems design that increases the probability that students will meet the important goals demonstrated in the PSI literature, The results of this experimental course provide important information about the strengths and weaknesses of the underlying principles of PSI and these will be discussed in detail.

The experimental course described by this paper was designed following a series of steps or phases which represent what is often called instructional systems design (ISD). ISD is an instructional problem solving method that takes the user through a series of steps and evaluation points that increase the likelihood that the instructional end product will be successful (Branson, 1981; Hannum \& Briggs, 1982). This paper will describe how ISD was used to prepare the course.

\section{AN OVERVIEW OF THE ISD PROCESS}

Figure 1 (see next page) presents a diagram of a basic ISD model. There are three important attributes of the model that should be noted. First, the thoroughness and sophistication of work done in one phase pays off at some future point. For example, if little effort is put into carefully looking for higher and more complex learning outcomes during the analysis phase, it is likely that the course may tend to emphasize only memorization type outcomes of the type identified by critics of PSI (Caldwell, 1985). Second, within each phase of ISD there are many procedures important to the success of the overall model. Although the extreme complexity of ISD often discourages would-be users, much of that complexity is important in the success of ISD (Dick Carey, 1978). Third, each ISD phase should result in some type of product. That product will not necessarily be the eventual instructional product. The importance of being able to evaluate and revise instructional plans and products during ISD is one of its strengths. Such an approach can often prevent the later occurrence of costly andtime-consuming mistakes. 
FIGURE 1. A Basic Instructional Systems Design (ISD) Model.

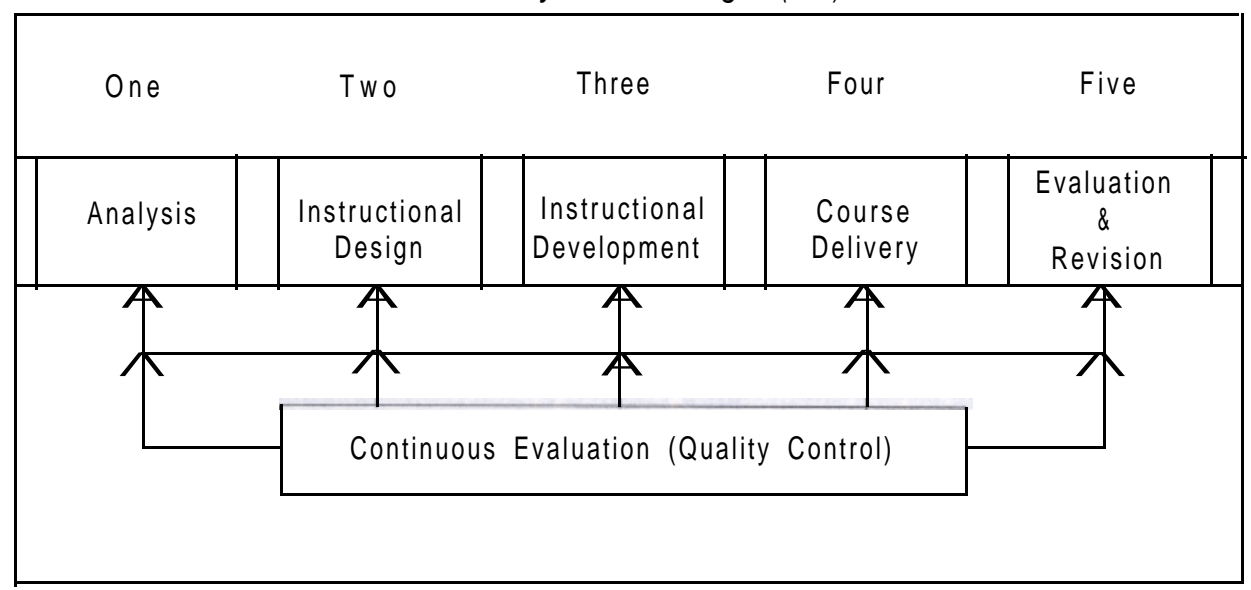

PHASE ONE: THE ANALYSIS PHASE

During the analysis phase all variables connected with the course are carefully scrutinized. These variables can be broken down into the following categories:

1) students (an analysis of their entering abilities, numbers, reading level, experience with individualized instruction, time availability, etc.);

2) available instructional materials (text selection, availability of ancillary study materials, etc.);

3) instructional environment (time available for instruction in semester and during each week, classroom space, grading policies, institutional rules connected with any aspect of the course, etc.);

4) learning outcomes (overall course goals, specific unit objectives, cognitive level of objectives, etc.);

5) instructor's attributes (ability to lecture, time availability, experience with innovative and individualized approaches to teaching, etc.); and

6) other (possible disruptions to schedule, need for equipment and supplies, etc.).

The product of the analysis phase consists of the answers to as many questions connected with the course plan as is possible. It is critical that all factors that could influence the course are clearly understood in advance and that the design of the course takes these into consideration. Moreover, during the analysis phase it is possible to confer with colleagues and supervisors in an effort to discover hidden factors that may prove important to the eventual product. The following sections describe some of the analysis done for the experimental course at Concordia College.

\section{Students}

The majority of students entering Concordia College are high school matriculation graduates seeking an undergraduate degree. A small number are adult students and 
students who have certain deficiencies in their high school education. The class sizes for introductory psychology have ranged from approximately 35 to 60 students.

Introductory psychology is a popular option course for many students whose career goals vary widely. Very few students have had any experience with individualized instructional techniques at the university level. Students at Concordia College are encouraged to spend approximately 2 hours in study for every hour of lecture and so for the introductory psychology (3 credits) course students are expected to spend about 6 hours per week on the course.

\section{Available Instructional Materials}

Concordia College is a small junior college with a correspondingly small budget. Computer resources are not available for students taking introductory psychology. Overhead projectors, video equipment and other instructional aids are limited. The most important instructional materials are the textbook and study guide. Introductory psychology is offered as two, single semester courses, the first course covering the more scientific side and the second semester covering the more applied side of psychology. A textbook that treats both sides adequately is necessary since most students take both courses. Observations over the past several years suggested to us that readability is an important factor when selecting a textbook. A well prepared test manual was considered to be an important requirement as well. The availability of a commercially available student study guide was also considered important, although the instructor was prepared to design a study guide specifically for the course.

\section{Instructional Environment}

The introductory psychology course generally requires that students attend class 3 hours per week over a 13 week semester. Classrooms are small and a policy of the college is to maintain a small class atmosphere. Students are graded on a 1 to 9 scale that in some courses is competitively determined and in others is determined according to achievement. Concordia College does not have strict rules regarding how grades are to be assigned, although many instructors tend to use the University of Alberta's guidelines in their grade assignments. Students are not normally permitted to complete course work beyond the end of the semester. For this reason self-pacing seemed unworkable.

\section{Learning Outcomes}

Introductory psychology is a general survey course covering diverse areas from physiology to sensation, perception, learning and memory. Students are usually required to write two examinations during the semester and one comprehensive final at the end of the semester. These examinations tend to be objective and test basic knowledge of course content. Objective examinations have been the measurement technique of choice primarily because of the large numbers of students taking the course. The overall goal of introductory psychology courses in most institutions is to provide students with a general knowledge of the various areas within psychology. Advanced courses can then be selected by students who wish to study specific fields in more detail. Students typically find out what they are expected to be able to do only when 
they write their first examination. Thus, providing clear and concise learning objectives for each unit of material was considered to be of prime importance in designing this course.

\section{Instructor Attributes}

The first author had taught introductory psychology at Concordia College numerous times over the preceding 7 years. Class size had usually been low and several sections of the course were taught each semester. One of the motives for redesigning the course involved avoiding repetition of lectures within a single day. It was not uncommon for the instructor to give the same lecture three times in one day. Although student evaluations of the instructor's lectures were very positive, our analysis suggested that eventually quality would decrease as the repetition of similar lectures often tends to become overly routine and somewhat boring.

\section{Other Factors}

Concordia College is a small school and students tend to know each other and collaborate in their studies. This placed certain restrictions on how examinations were to be prepared, monitored and graded. In any PSI type format there is usually a great deal of testing. Feedback on tests should be provided as quickly as possible and without a computerized testing system, this placed certain restrictions on how the course could be designed.

Many instructors using the PSI approach solve the many problems involved in frequent testing with the use of student proctors who have completed the course. Concordia College is a two year transfer school making the availability of student proctors limited and the use of a proctoring system impractical.

\section{PHASE TWO: THE DESIGN PHASE}

Once the analysis is completed the design of the course can begin. The result of the design phase is not the course or course materials, but a type of blueprint for the course. This blueprint specifies the details of the course, what comprises the course, how it will be delivered and managed, and how it will be evaluated. The course design represents the information obtained during the analysis phase.

The benefits of having a blueprint prior to actually constructing the course are many. First, the blueprint is much less expensive in terms of time and resources than course development. As is the case in building a house, the blueprint can be discarded or revised much more cheaply than can the house if something is not right or does not work. Second, the blueprint can be inspected by people who have an interest or stake in the product. It is far easier to revise the blueprint because the Dean has a concern over the grading scheme than it is to redesign the course itself. Third, administrative concerns, such as textbook ordering and study guide printing requirements, can be anticipated at an early date. Many PSI courses have been severely disrupted because the study guide was not ready or the texts did not arrive on time. Finally, the blueprint makes the course development job much easier. The instructor feels confident that the 
plan is workable and acceptable. the objectives and size of the course development job are made clear by the blueprint and that allows the instructor to proceed with development of study guides, examinations, and other materials according to already set plans. A brief description of the experimental course blueprint is described below.

\section{Students}

The majority of students are high school graduates, and the course was designed to meet their needs. The needs of the older adult or academically deficient students were not specifically considered. Class size was limited to 35 students for the first two sections of the course.

\section{Course Materials}

McConnell's (1984) text Understanding Human Behavior, 4th Ed. was selected as the text for several reasons. The book covers the entire field in a readable manner. Also, an excellent test manual was available in both print format and on floppy disc.

A study guide was prepared by the first author to accompany the text. The commercially prepared study guide did not match the requirements of the course and it was decided that a guide designed specifically for the course was preferable to using bits and pieces of the available guide. The study guide provided comments, supplemental material, and corrections to the text in the few cases where this was necessary. The most important part of the study guide was the list of learning objectives for each unit in the course. Objectives were prepared carefully and the tests were constructed with these objectives in mind. The study guide also provided information on study methods, test-taking and other details of the course. Students were also provided with a written course description that described the organization of the course, the expectations of the instructor, the grading schem, and the test format.

\section{Course Organization}

The material to be covered in the course was organized into 11 units, each corresponding to a chapter in the text. Students were required to complete one unit each week. The first week was devoted to orienting the students to the course format; the last week was used to review, evaluate and discuss the course.

The first class hour of each week was a lecture. Because the instructor's lecture ability was a positive attribute it was decided to retain this teaching technique for part of the course rather than to completely eliminate lectures as is often done with PSI. This lecture usually covered interesting aspects of the unit being studied, although in some cases the lecture clarified more difficult text material. The second class hour was used to test the students on the objectives for that unit. The third class hour provided a retest option for students who had not met the mastery criterion on the initial test.

\section{Test Format and Pass Criterion}

A primary goal of most PSI courses is student mastery of clearly specified learning objectives. The mastery criterion is usually very high. In the present course each unit examination consisted of 20 to 30 multiple-choice questions, each corresponding to a specific learning objective. Students were expected to correctly answer $80 \%$ of the 
items. Students' unit examination scores were provided within an hour or two of the examination. Students who failed to meet the $80 \%$ criterion were required to take a retest. Students were expected to answer $75 \%$ of the items on the retest. Students who answered below $75 \%$ on the retest were given one more opportunity to achieve success by completing a remedial assignment on the objectives for the unit.

A final examination at the end of the course covered all the material and corresponded to the more important and general objectives provided in the study guide. No provisions were made for retests or remedial work after the final examination was taken, although an optional assignment for bonus points could be completed by all students.

\section{Course and Grading Policy}

Grading was determined by the number of points accumulated by the students during the course. The entire course consisted of a maximum of 1600 points. Each unit test consisted of 100 points with 80 points required for reaching the mastery criterion. The retests consisted of 80 points with 60 required for mastery. The reduced points available on the retest were intended to reduce the likelihood that students would wait and write the retest after 'conferring' with another student who had written the test. After writing all 11 unit examinations, students could accumulate a maximum of 1,100 points. The final exam consisted of 400 points and a bonus of 100 points could be earned by completing an optional assignment. The unit examinations, the final examination and the optional assignment accounted for $69 \%, 25 \%$, and $6 \%$ of the course, respectively.

One interpretation of the self-pacing feature is that students would be able to complete the course whenever they had completed all course requirements. Concordia College's policies would not allow for this self-pacing aspect. Students were required to complete the course requirements by the end of the semester.

The grading scheme used by Concordia College is based on that of the University of Alberta and grades range from 1 through 9. The University of Alberta suggests a frequency distribution that can be used for large classes and produces a negatively skewed distribution of grades with a mean of approximately 6. This distribution is produced by assigning grades based on suggested proportions of the total. For example, a grade of 9 might be assigned to the top $2 \%$ of the class. This distribution is only a guideline and instructors retain a great deal of flexibility in grade determination.

The grading scheme for the present course was based on achievement only with a minimum points requirement established for each grade. This scheme is presented in Table 1 (see next page). Students received a description of this scheme along with the rest of their course package.

\section{PHASE THREE: THE INSTRUCTIONAL DEVELOPMENT PHASE}

Once the blueprint has been found to be satisfactory and complete, the development of the course can begin. Instructional development usually involves following the guidelines described by the design blueprint. That does not mean that instructional 
TABLE 1

\section{First Semester Grading Scheme}

\begin{tabular}{|c|c|c|}
\hline 1200 & points & 9 \\
\hline 1100 & points & 8 \\
\hline 1000 & points & 7 \\
\hline 900 & points & 6 \\
\hline 800 & points & 5 \\
\hline 700 & points & 4 \\
\hline 600 & points & 3 \\
\hline 500 & points & 2 \\
\hline$<500$ & points & 1 \\
\hline \multirow{2}{*}{\multicolumn{2}{|c|}{$\begin{array}{l}\text { Unit Tests: } 11 \text { Units @ } 100 \\
\text { Final Exam }\end{array}$}} & 1100 \\
\hline & & 400 \\
\hline \multicolumn{2}{|c|}{ Optional Assignment } & 100 \\
\hline
\end{tabular}

development cannot become extremely complex and time consuming. This is especially the case when instructional materials are being developed from scratch or when the blueprint calls for the use of high technology (e.g., computerassisted instruction, videotape, etc.). Anyone who has produced programmed instructional materials will understand the range of alternatives and the skills required during the instructional development phase.

For many college and university courses the instructional development phase does not involve the development of original instructional material. Such courses use a textbook and a commer-

cially produced study guide as the primary self-instructional materials. These are frequently supplemented with study guide materials produced by the instructor to meet the needs of the particular course and delivery plans specified in the design blueprint.

At a minimum, college and university courses that are designed to utilize an existing textbook or instructional package will require the development of the following instructional components:

1) instructional objectives and/or study questions to direct the learners attention to important course content;

2) advance organizers and commentaries to highlight important concepts, explain concepts not well explained in the text, or provide additional information not covered in the text (e.g., information, examples, rules, etc.);

3 ) practice exercises and self-study questions that give learners an opportunity to test their knowledge of the unit objectives;

4) criterion tests and answer keys for use in monitoring student performance on each unit in the course. Often multiple forms of these are needed; and

5) student information handouts (i.e., a student manual for the course), that describe the course procedures and the grading scheme.

\section{PHASE FOUR: COURSE DELIVERY}

This is the phase that is most representative of conventional college and university instruction in that lectures are presented, tests are given, questions are answered, and eventually grades are awarded. Course delivery following the ISD model is comparable to conventional course delivery. The details of the delivery plan have been worked out during the instructional design phase and are described both in the design blueprint and the student manual for the course. 
There are a few procedural and mechanical activities that are important during the delivery phase. First, careful records of student performance must be kept and secured. Second, all personnel connected with course delivery (e.g., instructors, assistants, proctors, etc.) must be supervised and given help when needed. Third, even the most carefully designed course will have problems during initial delivery. The instructor must be prepared to make quick revisions and to solve problems as they occur. Finally, and perhaps most important, the instructor should be available to meet with students, demonstrate enthusiasm for the subject matter and the course, and should demonstrate a level of professionalism common to good college and university teaching. There is nothing about the ISD or the PSI approach that reduces the need for direct instructor interaction with students when it is appropriate.

\section{PHASE FIVE: EVALUATION AND REVISION}

The last phase the ISD model involves two distinct activities. First, a comprehensive evaluation of all aspects of the course should be planned and carried out. Given that it is unlikely that all instructional components and procedures will work perfectly the first time, it is important to find the problems and the strengths. Second, the results of the evaluation must then guide careful revisions of the course. The importance of building an empirical base for instruction has been emphasized elsewhere (Semb, 1976) and is an integral part of the ISD approach. The evaluation and revisions suggested by our results are presented in the remainder of the paper.

\section{RESULTS}

The results of offering this experimental course are presented in three sections. The first describes the results of the first semester course which was offered as a modified PSI course offered. The second section describes the results of offering the second half of the course in the conventional lecture-discussion format. The third section describes the results of the PSI course after evaluation and revision of the first semester course in section one. A discussion of the problems encountered during course delivery is also presented.

\section{Semester One Results}

It was clear that the instructional aspects of the course could not have started the first week of the semester. It took the first week to explain the course format. Several students did not attend the first day of class and the textbook was late in arriving at the bookstore. Had the course begun the first day of class, many students would have missed the first test or not been prepared for it.

Some of the study guide objectives appeared to be too specific. This became evident when creating test questions that required more general knowledge than that precisely stated in the objective. In addition, some objectives were too broad and students were unclear about the requirements of the objective. Objectives beginning with the word 'explain' were particularly troublesome to some students and these were 
changed using terms like 'describe' and 'list'. Overall, however, students reported satisfaction with the study guide.

Several problems developed with the tests and retests. The tests were prepared as the course progressed to allow modifications to be made. Several students did not reach criterion on the first unit test. It would have been desirable to construct the first test to ensure that most, if not all, students would succeed. Positive feedback early in the course can be an effective factor in maintaining higher levels of performance throughout the course (Skinner, 1968). Successful early experience should have been a course goal.

The first few units had only one form of the test and one form of a different retest. This was changed so that two versions of each form of the test were available. Students who failed to reach criterion on the test then took the alternate version as the retest. Some difficulties arose when students were close to mastery but still below the criterion. It would be desirable to construct tests so that borderline performance would be less likely to occur or could be adjudicated by the instructor.

The remedial assignments for students who had failed a retest involved writing clear answers for each objective listed in the study guide and handing these answers in at the next class meeting. Most students did this routinely when they prepared for a unit test and as a result it may not have been a particularly valuable technique in terms of remediation.

The optional assignment involved having students complete an essay describing the main points of one of the chapters not covered in the course. This assignment was done by most students even when it had little effect on their grade. The quality of work was not very high, presumably because the reinforcer (100 points) was not very powerful. Students seemed to hand in the assignment as a matter of course. Grading these assignments was somewhat difficult due to their lack of conformity in format or style. Providing more structure for the assignment would have increased the learning value of the exercise.

There was some concern that students would not attend the lecture because passing the test primarily involved studying the learning objectives and textual materials. In contrast, lecture attendance was very high. Presumably this would not occur if the lecture was of poor quality. Students did indicate midway through the course that they would appreciate a 15 minute period at the beginning of the lecture period to discuss any problems they were having with the learning objectives. Students were strongly encouraged to read the chapter and study the objectives before the lecture and most appeared to do so. Students being prepared improved the lecture because students were much more willing to participate by asking questions and answering questions posed by the lecturer. The grade distribution for the first semester course is shown in Table 2 (see next page). The large proportion of high grades was one of the major problems with the course.

Many students found themselves in a position of being able to do poorly on the final exam and still earn the top grade in the course. The range of 1,200 to 1,600 points for a top grade seemed much too wide and in fact several students with close to 1,600 points felt that their performance was much higher than those students closer to 1,200 points. These results suggest that the point requirement was too low, even though it did 
TABLE 2

First Semester Final Grade Summary

\begin{tabular}{cc}
\hline Grade & Frequency \\
\hline 9 & 51 \\
8 & 7 \\
7 & 7 \\
6 & 1 \\
3 & 1 \\
\hline
\end{tabular}

reflect approximately $80 \%$ of available points.

Attrition rate has been of some concern to users of the PSI approach. This did not appear to be a problem in the present course. Although students had the option of changing to a conventional section of the course, few chose to do so. Of a total of 71 students who began the course, two students withdrew from all studies and another two withdrew from

the course. One of these was a foreign student who had a great deal of trouble with the English language. The second was doing very poorly on the unit tests. An attempt to locate a tutor to work with the foreign student was made but the student withdrew from the course before this was achieved. A tutor was also assigned to the second student and this arrangement was successful for a short time.

The student evaluations of the course were positive. Students seemed to appreciate that the additional testing served to decrease the required study time for the final exam. The great majority indicated that they learned more in this course than in others and found that they benefited a great deal by studying for a test every week. The only consistent criticism concerned the leniency of the grading scheme.

The final grade distribution is presented in Table 2. As this distribution indicates, there were many high marks. An analysis of the low marks indicated that the students typically failed to write several unit tests and when they did write tests often did not reach mastery on the first attempt.

\section{Semester Two Results}

Thirty-two of the students who participated in the experimental section of the first semester course continued with the second semester course of introductory psychology with the same instructor. Nine students continued with a different instructor. The second semester course was taught by both instructors using the conventional lecturediscussion method. Course grades were assigned based on two examinations and one cumulative final examination. Grades were determined according to the suggested guidelines provided by the University of Alberta. Table 3 (see next page) presents the final grades for the previous PSI students and for a comparison group of students who had taken the first course under conventional instruction.

Inspection of the frequency distribution indicates that the previous PSI students performed somewhat better than the conventional comparison group. Some critics of the PSI approach have suggested that students become dependent on the increased structure provided by the PSI format and have difficulty adjusting to a more conventional instructional technique. These results would not support this conclusion.

Students finishing both semesters of the course were asked to evaluate the semester just completed (conventional lecture-discussion) in comparison to the first semester course (modified PSI). The evaluation indicated clear preference for the modified PSI course. Students indicated that they felt very well prepared for the second semester course and had no problems adjusting to the change in format. 
TABLE 3

Second Semester Grade Summary

\begin{tabular}{ccc}
\hline $\begin{array}{c}\text { Grade } \\
\text { Point }\end{array}$ & $\begin{array}{c}\text { Previous } \\
\text { PSI }\end{array}$ & $\begin{array}{c}\text { Conventional } \\
\text { Comparison } \\
\text { Group }\end{array}$ \\
\hline 9 & 3 & 2 \\
8 & 3 & 5 \\
7 & 10 & 3 \\
6 & 9 & 18 \\
5 & 9 & 8 \\
4 & 5 & 4 \\
3 & 1 & 1 \\
N & 40 & 41 \\
Drops & 1 & 0 \\
M & 6.07 & 6.0 \\
\hline
\end{tabular}

TABLE 4

Third Semester Grade Summary

\begin{tabular}{cc}
\hline Grade & Frequency \\
\hline 9 & 8 \\
8 & 21 \\
7 & 11 \\
6 & 5 \\
5 & 5 \\
4 & 1 \\
3 & 1 \\
\hline
\end{tabular}

\section{Semester Three Results}

Based on the results from the first semester SLI course, a second SLI

course was conducted the following year. Fifty-two students began the course. The adjusted grading scheme required 1,300 points out of a possible 1,500 for a top grade of 9. The optional bonus assignment was eliminated. Some of the test questions were altered because of problems that arose when they were used in the first course.

The final grades are presented in Table 4 . The change in point requirements for grades decreased the number of $9 \mathrm{~s}$ and increased the range. This scheme seemed more in line with other college and university courses, although the grades were still higher. Students obtaining $8 \mathrm{~s}$ and $9 \mathrm{~s}$ were performing at $80 \%$ mastery on all tests and the final exam. The unit tests and final exam were of similar difficulty and content to tests used prior to the course and to tests used by other introductory psychology instructors.

\section{DISCUSSION}

This paper has presented a model for course dcvclopment utilizing a behavioral approach to instruction within the context of instructional systems design. The importance of both the ISD approach and the principles critical to the success of PSI will be discussed.

In a recent interview Keller (1984) indicated concern over the number of people who claimed to be using PSI as their instructional technique but were only using some of the features while often omitting critical features. Keller referred to this approach as SLI (not PSI but Something Like It). Moreover, many PSI experts called upon to teach others to use PSI often required strict adherence to the PSI features and tolerated little modification or adjustment to these features. In contrast, using PSI in the context of an overall ISD approach allows the user to do SLI in a way that capitalizes upon the strengths of PSI while systematically dealing with many of the problems inherent in college level instruction. An ISD approach becomes a way of dealing with the many 
issues and concerns that are important to the success of any individualized instructional method.

The 'something like it' PSI course that resulted from this effort retained many of the most important features of PSI, including mastery grading, small units of material, immediate feedback on performance, an emphasis on written instruction with supplementary lectures, frequent quizzing, and an opportunity for remediation when required. The main PSI features not used were complete self-study, self-pacing, and the use of proctors. However, within each week of the course there was a large degree of selfpacing, albeit unit examinations were scheduled at specific times throughout the week.

The important aspect of ISD as a systematic instructional problem solving tool is that it is possible to use it to look more generically at instructional options and blend them together into a functional instructional system. It is clear from the PSI literature that PSI was constructed in response to a need for improvement over conventional lecture-discussion methods and that the features of PSI developed from basic behavior principles and practical requirements of implementation of those principles. Keller, no doubt, had to systematically consider each feature in relationship to other features in order to design a particular PSI course. That process is more sophisticated than simply implementing a fixed set of features and perhaps explains why PSI was not implemented successfully in some cases. Instructors may have simply picked a point on the continuum of a given feature that handicapped the overall PSI system (e.g., designing three unit tests for a course as opposed to the conventional single final examination in order to do 'frequent' testing. Such a decision would make the remaining features of the system and the underlying PSI principles of little use).

After the authors described the approach to the design of this course and the results with Keller, he indicated that such planning and the careful use of the PSI features represented an effective use of PSI (F. S. Keller, personal communication, May, 1985). Apparently Keller's concern about SLI courses is a concern over poor instructionaI planning and the misuse of behavioral instruction and not an attempt to encourage strict adherence to all the features of PSI. This is especially the case with features that may not prove important in a given context.

The improvement of college and university instruction is often viewed as an improvement to the components of conventional lecture-discussion techniques. The PSI model is a major departure from this approach and requires a major change in behavior and attitude on the part of the instructor. Instructors who are dissatisfied with conventional instruction and are looking for alternatives will find that PSI may serve as a basic model. However, modifications to that model should be made systematically and the functional aspects of the PSI system preserved.

Instructors interested in considering adoption of PSI should be aware of a few important problems. First, as this paper has already discussed in detail, PSI may not be possible in its pure form for many instructors. Systematic modification to PSI requires considerable sophistication in instructional systems design. Experience implementing behavioral programs, especially ones connected with instructional intervention, would be an asset. Second, the front-end cost of systematically designing a PSI course is higher than conventional lecture/discussion courses. The majority of this cost is measured in terms of preparation time and costs of duplicating student guides, multiple 
forms of examinations, etc. However, once the course has been offered and the problems of implementation solved, the course requires less time than conventional courses. Duplicating costs can also be amortized across many students and reduced accordingly. Third, PSI courses tend to identify student problems with learning that more conventional courses hide. Instructors should be prepared to deal with student learning and motivational problems that are made clear by the PSI system (e.g., inability to read effectively, not enough time to study to reach criterion, language difficulties, etc.). Fourth, the process of writing behavioral objectives can reveal just how much low level memorization behavior is required of students and covered in texts. Although there are instructional design options for increasing the level of objectives and corresponding materials and examinations, those skills require time to acquire and will often make conventional texts appear inadequate for learning at the concept or problem solving levels. These problems are often hidden in conventional courses that do not have clearly stated behavioral objectives. Finally, the underlying philosophy of PSI is that a significant majority of learners are capable of meeting most objectives if presented with an instructional system that supports such behavior. If an instructor simply does not believe that to be possible, it is unlikely that such an instructor will see the benefits of PSI. In contrast, if an instructor does believe it is possible and tries PSI he/she will likely begin to see both the strengths and limitations of the approach. The end result should be a course that maximizes the level of student achievement given the resources available.

\section{REFERENCES}

Branson, R. K. (1981). Application research in instructional systems development. Journal of Instructional Development, 4, 4.

Caldwell, E. C. (1985). Dangers of PSI. Teaching of Psychology, 12(1), 9-12.

Coldeway, D. O., \& Spencer, R. E. (1982). Keller's personalized system of instruction: A search for a basic distance education paradigm. Distance Education, 3(1), 51-71.

Dick, W., \& Carey, L. (1978). The systematic design of instruction. Glenview, IL: Scott, Foresman.

Hannum, W. H., \& Briggs, L. J. (1982, January). How does instructional systems design differ from traditional instruction? Educational Technology.

Keller, F. S. (1968). "Good-bye teacher". Journal of Applied Behavior Analysis, 1, 78 89.

Keller, F. S. (1984, September). Conversation with Fred Keller, "The revolutionary gentleman". Psychology Today, 44-48.

Kulik, J. A., Jaksa, P., \& Kulik, C. C. (1978). Research on component features of Keller's personalized instruction. Journal of Personalized Instruction, 3(1), 2-14.

Kulik, J. A., Kulik, C. C., \& Cohen, P. A. (1979). Meta-analysis of outcome studies of Keller's personalized system of instruction. American Psychologist, 34, 307-318.

McConnell, J. V. (1984). Understanding human behavior (4th ed.). New York: Holt, Rhinehart \& Winston.

R. S. (1976). An evaluative review of the personalized system of instruction. Washington: Center for Personalized Instruction. 
Semb, G. (1976). Building an empirical base for instruction. Journal of Personalized Instruction, 1(1), 11-22.

Skinner, B. F. (1968). The technology of teaching. New York: Appleton-CenturyCrofts.

\section{Call for Papers}

Dr. Robert M. Bernard, Editor

Canadian Journal of Educational Communication

Concordia University

Dear Dr. Bernard:

THE IMPORTANCE OF BEING WRONG

Many years ago I attended a lecture with the appealing title of "On the Importance of Being Wrong". Its thesis was that we can learn much more from a careful study of projects that fail, than we can from congratulating ourselves on those that succeeded.

Prompted by this idea, PLET 26(2) (Programmed Learning and Educational Technology) will be a special issue that concentrates on projects in educational and training technology that do not achieve their aims. The emphasis will be on a constructive analysis of the failure - examining the reasons why, and drawing lessons for the future. We all make mistakes and there are very few of us who can point to a perfect track record. An important skill is to learn from mistakes made by others!

So as the editor of the special issue, I would like to hear from those who have been involved in projects that failed-and would be interested in writing about it so that others can profit from their experience.

Please write or telephone as soon as possible to:

Nick Rushby

Sundridge Park Training Technologies

Plaistow Lane

Bromley, Kent

BR1 3TP UK $\quad$ TEL: 014608585

I look forward to hearing from you all!

Yours Faithfully,

N. J. 


\section{JOURNAL OF DISTANCE EDUCATION REVUE DE L'ENSEIGNEMENT A DISTANCE}

The Journal of Distance Education is a peer reviewed international journal of the Canadian Association for Distance Education (CADE/ACED), published at Simon Fraser University's Centre for Distance Education, Continuing Studies. The Journal is intended as a forum for the dissemination of current theory, research and practice related to teaching and learning at a distance. Papers (published in English and French) will deal with the following aspects of distance education:

${ }_{\varepsilon}$ learning and learning strategies

« instructional design

«s higher education

$\approx$ adult/continuing education

$\approx$ teaching at a distance «x international/development education $\approx x$ administration of distance education institutions

\&* student counselling/support services \& educational technology

\section{Please direct correspondence as follows:}

regarding subscriptions

CADE Secretariat

151 Slater Street

Ottawa, Ontario

KIP $5 \mathrm{Nl}$

Canada

\section{regarding submissions}

Dr. Dan Coldeway

Centre for Distance Education

Athabasca University

Box 10,000 Athabasca, AB

TOG 2R0 Canada

Potential authors are encouraged to submit articles for a special issue of Journal of Distance Education to be published in May, 1988 with the theme: Building bridges between conventional academic disciplines and distance education.

Deadline for submissions is 15 December 1987. 


\title{
The Value of Supplementing Panel Software Reviews with Field Observations
}

\section{Ronald D. Owston Herbert H. Wideman}

\begin{abstract}
When purchasing software for classroom use, educators frequently have to rely on software evaluation reports in making their decisions. Unfortunately, most reports do not make clear the extent to which the software being reviewed has been field tested or whether it has been field tested at all. In this study, teacher panel reviews of software were compared to field test reports to determine the levels of agreement between the two evaluation types and what kinds of additional information can be obtained from field observations. The results suggest that field testing may: a) bring to light technical and design limitations that are not obvious to teacher reviewers; b) provide more accurate information on the ease of use of the software; c)suggest unique ways in which the software can be used in the classroom; and d) give a clearer indication of the suitability of software in meeting specialized student needs.
\end{abstract}

Educators interested in carrying out summative evaluations of microcomputer software face no shortage in evaluation models from which they can choose. A search of the literature on software evaluation can easily turn up over 50 different evaluation forms, checklists, or complete models, and there are as well perhaps hundreds of unpublished forms developed for local use. All of these procedures usually provide a series of questions or a set of rating scales to guide the teacher or other expert in assessing the content and instructional quality of software. They normally place little, if any, emphasis on gathering data by means of direct observation of students' use of a program and on reporting these data. This is true of even the most widely used evaluation methods; for example, the evaluation guidelines published by the National Council of Teachers of Mathematics recommend only that 'two or three' students be observed during one use of the program, with most of the data for the evaluation being collected in the course of the teacher's use of the package (NCTM, 1984). MicroSIFT's widely used evaluation procedures do not require evaluators to observe students working with the software to complete their checklist, although this is left as an option (ICCE, 1984). MicroSIFT had intended to engage in field testing of software as the

Ronald D. Owston is Associate Professor of Education and Director of the Centre for the Study of Computers in Education, Faculty of Education, York University, 4700 Keele St., North York, ON M3J 1P3. Herbert H. Wideman is Research Associate in the Centre for the Study of Computers in Education. 
fourth stage in their own evaluation activities, but this was never done. The Educational Products Information Exchange does require its evaluators to field test software until a consensus is reached about its quality, but there is no reference to any field test findings in their published reports (EPIE, 1986).

As the EPIE case illustrates, even when the evaluation procedures themselves may specify that field testing bc carried out, often there is no clear indication from the evaluation report whether, or to what extent, it was actually undertaken. The reader is typically given summary ratings and evaluative comments. Seldom is there any indication of the number of evaluators used, the length of the evaluation observation period, student responses, the type of school and classroom, or the age/grade of the students involved in the field test.

Nearly all the major models of educational evaluation, from Tyler's objectivesbased design to more recent formulations such as Guba and Lincoln's responsive model and Eisner's advocacy of educational connoisseurship, emphasize the importance of gathering data from program users (Eisner, 1979; Guba \& Lincoln, 1981; Tyler, 1950). More recently, there has been increasing demand that courseware reviews meet these criteria (e.g., Muller, 1985; Pike, 1983; Ragsdale, 1982; Tovar \& Barker, 1986).

Evaluation consumers need to know whether an evaluation report is based on field testing because the ultimate test of the value of a software package is its effectiveness in the classroom with users. Software producers certainly cannot be relied upon to provide this information; a recent survey of producers found that only half of the 125 respondents did any form of field testing, and just $12 \%$ of those included the results in their product documentation (Truett \& Ho, 1986). Educators may have the expertise to assess the quality of a program's content and instructional design, but it seems unreasonable to assume that they will be able to judge with any precision how students will respond to it. There is practically no research available that investigates how well teacher reviews are able to predict the classroom effectiveness of software. Certainly, if a consumer reads an evaluation report that was not based upon classroom observation, he or she has no reliable way of knowing how effective the software would actually be. The results of one study that has compared students' and teachers' perceptions of a series of algebra programs designed to complement classroom instruction do not encourage reliance solely on teacher ratings. Students proved to be stronger critics of the software than the teachers, rating it lower on adequacy of pacing and on instructional and motivational value (Signer, 1983). Other research suggests that, even when well trained, teachers are often uncritical of software they evaluate (Preece \& Jones, 1985). Elementary and middle school students, on the other hand, can frequently make 'mature and sophisticated' judgements about a program's quality (Smith \& Keep, 1986).

Experimental and quasi-experimental research has recently been advocated as being the most rigorous means for judging a program's effects (e.g., Muller, 1985; Tovar Barker, 1986). While these forms of evaluation can be most effective in minimizing threats to the validity of some forms of outcome data, practical limitations on the resources available for software assessment often restrict the number of packages that can be evaluated in this manner. Alternatively, the use of trained teachers, working independently, to observe and record student reactions to software and to 
conduct student interviews would greatly increase the number of field tests that could be undertaken. While there would be an inevitable decrease in the amount of information gleaned about program outcomes, the collection of dam on students' affective and cognitive responses to different aspects of a program's content, design, and technical quality should provide a significant body of information which would substantially enhance the quality of teacher software reviews.

\section{THE STUDY}

The present study was designed to provide an assessment of the incremental value of one form of qualitative field testing undertaken by teachers working independently. A number of programs previously evaluated by panels of educators were field tested by teachers in their classrooms. (Both evaluation procedures are discussed in some detail below.) Qualitative comparisons were made between the panel and field evaluations of each software package in order to determine the extent to which the two kinds of data diverge and to assess the value of the contribution of the additional data obtained from the field test to the overall evaluation of the software. The data analysis had two parts. First, each comment and scale rating in the panel evaluations was coded as agreeing, disagreeing, or being supplemental to the comments in the matching field test report. In addition, field test remarks that contained information supplemental to that in the panel evaluations were coded as such. Coding was completed by each author independently; inter-rater agreement was found to be over $90 \%$. The few discrepancies were resolved through discussion. In the second phase of the analysis, comparisons were made between the different pairs of evaluations using the constant comparative method (Glaser \& Strauss, 1967). Substantive theories were developed about the overall trends in agreement, disagreement, and supplementation between the two forms of evaluation. These served as the basis for assessing the incremental utility of the field tests.

Thirty-six commercially available software packages were studied covering primary and junior level mathematics, language arts, reading, and general problemsolving skills. These included a variety of types of software ranging from drill and practice to more open-ended problem-solving packages.

\section{Evaluation Procedures}

A two-stage summative software evaluation model developed at York University Faculty of Education makes clear the role of field testing in software assessment. The model separates the evaluation process into two distinct phases teacher review and field testing. Each phase has its own unique procedures, yet both yield evaluative data in the same categories.

Panel Evaluation. The first stage of the model is called panel evaluation (Owston, 1987). At this stage, groups of three teachers develop a consensus on what the rating of a software package should be using the York Educational Software Evaluation Scales (YESES). YESES is a set of four criterion-based scales that provide a more global or holistic assessment of software than is possible with the more commonly-used checklist approaches. It is more holistic in the sense that evaluators judge the overall quality of 
the software using only four scales, rather than responding to a lengthy series of questions typically found in checklists. The four scales of YESES are pedagogical content, instructional presentation, documentation, and technical adequacy. The pedagogical content scale refers to the knowledge and skills that the software purports to teach, including their organization, accuracy, and appropriateness; the instructional presentation scale is concerned with the manner in which software takes advantage of the unique features of the microcomputer in presenting the content; the documentation scale refers to the supporting materials and instructions, available both in print and on screen, that accompany the software and explain its use; and the technical adequacy scale is concerned with the quality of the software design with respect to user inputs, software outputs, and system errors. For each of these dimensions, there is a four-point scale that describes the general characteristics of software that would be rated at that level. Software rated level 4 is labelled 'exemplary', level 3 'desirable', level 2 'minimally acceptable', and level 1 'deficient'. Figure 1 provides an illustration of the pedagogical content scale of YESES.

\section{Figure 1. Pedagogical Scale of YESES.}

\section{DEFINITION}

Content refers to the knowledge and skills the software purports to teach the organization, accuracy, and appropriateness of the material. Content organization refers to the sequencing of the knowledge and skills within the lesson or lessons, the breadth or scope of the skills and knowledge, and the depth of instruction or amount of practice given to a topic. Accuracy is concerned with the truthfulnessof the knowledge and skills presented. Appropriateness deals with the suitability of the content for the intended user, including such factors as readability, the relationship between the complexity of the content and the intended user's ability to master it, and the educational value of the content (i.e., whether the time spent learning the content is justified because of its inherent value). If one or all of these elements - organization, accuracy, and appropriateness - are weak, the content may be judged less than exemplary.

\section{Level 4: Exemplary Content}

Level content is superior in its organization, accuracy, and appropriateness. The content organization is such that the scope of the knowledge and skills is congruent with the user's ability to master them, the sequencing is logical and follows good pedagogical practice (e.g., less abstract ideas are presented before more abstract ideas), and the depth of instruction is sufficient to give the user adequate practice before proceeding to the next topic. The accuracy of Level 4 content is extremely high. Furthermore, the content at this level is very readable, well-matched to the intended user's ability to master it, and has high educational value.

Continued on next page. 
Figure 1, continued. Pedagogical Scale of YESES.

\section{Level 3: Desirable Content}

The organization, accuracy, and/or appropriateness of Level 3 content is not quite as favorable as that of Level 4 due to relatively minor weaknesses. The organization may be weak because the content scope does not quite match the user's ability to master it; the sequencing may be illogical or not in keeping with accepted pedagogical practice; the intensity of instruction may be either slightly more or less than necessary, requiring the user to complete too many or too few exercises; and the user may not receive sufficient practice with the material before moving on to the next topic. Problems with accuracy might consist of questionable (but not incorrect) facts or applications of concepts. Level 3 content may also present some vocabulary or sentence structures that give intended users difficulty. Its material may be too complex or too easy for the intended user to digest, and some aspects of the content may be of questionable educational value. However, all flaws in Level 3 content are slight.

\section{Level 2: Minimally Acceptable Content}

Level 2 content is weak in either one area or a combination of the areas of organization, accuracy, or appropriateness. The deficiency, however, is not serious enough to prevent the use of the software, if no other better software is available, and if the instructor is able to rectify the deficiency. In its organization Level 2 software may present too much material; it may be poorly arranged in sequence or not consistent with good educational practice; its instructional depth may be exaggerated or insufficient. Accuracy problems encountered with Level 2 content include incorrect minor facts or applications of concepts. At this level vocabulary and content structure may be too difficult for the intended user, the knowledge and skills too difficult to master (or too easy), or the educational value of the overall content questionable.

\section{Level 1: Deficient Content}

Content at Level 1 is sufficiently substandard to call into question the use of the software, regardless of the strengths of its other characteristics. Organizational problems may include weak, illogical sequencing, and content scope and/ or depth of instruction poorly matched with the user's ability. This Level of content may also contain factual inaccuracies or incorrect applications of concepts. The content reading level may be inappropriately matched with the user's ability, the knowledge and skills presented eithertoo complex or simple, the topicscovered of dubious educational value.

The design of YESES was influenced by developments in three areas. The first is the field of the assessment of writing and, in particular, the analytical method of scoring writing (Diederich, 1974). In this field, the assumption is that there are several identifiable underlying traits of writing, all of which, in any context, are considered important, upon which the writing can be judged. Scales are constructed to measure each of these key traits, with each scale point being explicitly defined to describe writing characteristics of that level. The second field is criterion-referenced testing 
(Popham, 1978). Here the belief is that more meaningful assessments of achievement, for example, can be attained by determining the extent to which specific domains of knowledge have been mastered, rather than by basing the assessment on achievement relative to others taking the test. Assessment of second language oral proficiency is the third area from which the rationale for YESES is drawn. Specifically, those techniques that enable teachers, through loosely structured interviews, to rate a student's overall proficiency according to pre-defined criteria were examined (e.g., NBDE, 1974). The ideas of these three fields were influential in the design of YESES in that: a) four key characteristics of software were identified; b) criteria against which software would be judged were specified before evaluations were made; and c) evaluators have to make global assessments in each of the scale areas about the overall quality of the software.

In panel evaluation, the process is one of becoming thoroughly familiar with the software and then determining which level of YESES best characterizes the software for each of the four dimensions. The final step requires evaluators to write short evaluative comments, mentioning any unique features of the software and its possible applications, strengths, and weaknesses. When both the panel ratings and the written notes are combined, the reader obtains an overall impression of the quality of the software from the panel's perspective.

Evaluators were given a one-day training session on the use of the instrument. The training session consisted of an in-depth introduction to the rationale, design, and interpretation of YESES. This was followed by a 'hands-on' experience in which individuals evaluated a software package that has been rated previously by the original calibration group involved in the development of YESES. A group discussion was then held during which time the original calibration group's ratings of the software were revealed and evaluators were given the opportunity to raise questions and seek clarifications. Evaluators then had the opportunity to do at least one more practice evaluation.

The inter-rater reliability and validity of the panel evaluation process have been found to be reasonably high (Owston, 1985, Owston \& Dudley-Marling, 1986). When a software package is rated by the same panel on two different occasions, or by different panels, the ratings are, without exception, found to differ by no more than one or two points on one, two or three of the four evaluation scales. This level of reliability is realized because of the training evaluators receive in using and interpreting YESES and because of the use of explicit criteria for the scales of YESES. When a sample of panel evaluations were compared to evaluations of the same products done by EPIE, there was agreement or partial agreement on the overall value of the products in $71 \%$ of the cases. Further support for the validity of the YESES procedures can be found by observing the high level of agreement between software packages that are 'recommended' by Alberta Education (1986) and those that receive 'exemplary' ratings on all four scales of YESES.

Field Testing. Field testing, the second of the two stages in the York evaluation model, requires that software be tried out in a classroom for four to six weeks (DudleyMarling, Owston \& Searle, 1986). Common guidelines for conducting field tests were given to teachers and a group discussion was held on their use. The guidelines call for the teacher to observe children using the software and informally record their reactions. These notes are later used by the teacher for organizing a discussion with students 
about the software. Both the teacher observational data and student data are then grouped into the categories of YESES that most appropriately describe them. At this point a narrative report of two to three pages is written. In addition to the observations, the teacher reports on the dates when the evaluation was carried out, the hardware used, and the curricular context and instructional setting in which the evaluation took place. Only teachers who had had experience in conducting panel evaluations were used for field testing software. Furthermore, teachers did not field test the same products that they evaluated in panels.

In brief, the field test report describes how one teacher used a given software package in a particular setting and what results were obtained. The extent to which the results would be applicable to other settings will depend upon the similarity of the two settings. Thus the field test should be viewed as information to supplement the panel evaluation, not as a summative evaluation in its own right.

\section{RESULTS}

The comparison of the panel evaluations with the corresponding field tests proved illuminating. In 19 of the 36 pairs of evaluations that we have studied, the two forms of software review have been in general agreement about the quality of the software tested. In 10 cases, the two evaluations offered strongly divergent assessments of the quality of the software. And in the remaining seven instances, the panel and field evaluations concurred on certain aspects of the software's quality but disagreed on others.

For the programs about which there was general agreement, those given 'desirable' or 'exemplary' ratings for content and instructional presentation in the panel evaluations were found by the field testers to be effective learning aids that held students' interest and made good use of the computer's capabilities. The packages considered inadequate or barely acceptable by the panels were those that the field testing indicated had little educational utility because of inappropriate content or poor design. The evaluations and field tests were usually also in agreement about several other aspects of the software, such as the quality of the screen displays and the documentation, the ease of program operation, and the adequacy of the feedback and on-line help.

The evaluations of The Puzzler program, shown in Figure 2 (see next page), provide an illustration of the level of agreement between the panel and field findings typical of the majority of cases. The panel evaluators rated the content, instruction, and technical quality of the program as 'desirable', and the documentation as 'exemplary'. They noted in their comments that the novelty of the material should stimulate interest, and that the program invited divergent thinking and shared reading experience.

The students' experiences with the software, as reported by the field tester, seemed to bear out the panel's evaluation. The teacher noted that the students maintained a high level of interest in the program and completed all of the relevant tasks. The students cooperated with each other in problem-solving, interacting frequently as they analyzed choices and made predictions. The documentation, which the panel had considered comprehensive and exemplary, proved extremely helpful to the teacher in integrating the program with the curriculum. 
Figure 2. Sample Panel Evaluation and Field Test Report.

\title{
YORK PANEL EVALUATION RESULTS
}

DATE OF EVALUATION (YY/MM/DD): 85/03/01

EQUIPMENT USED: Apple lle

EVALUATORS: SE., L.H., J.F.

TITLE: The Puzzler

RATINGS (4-exemplary, 3-desirable, 2-minimally acceptable, 1 -deficient)

\section{CONTENT 3 DOCUMENTATION 4 \\ INSTRUCTION 3 TECHNICAL 3}

Comments:

The content of this program is based upon a sound theoretical framework, reflecting contemporary approaches to the teaching of reading. The material offers a supplement, although not a substitute for the regular reading materials. The effects of novelty could serve to stimulate interest particularly for the less able student. The open-ended nature of the material invites divergent thinking and permits shared reading experience. The documentation offers a comprehensive package which clearly integrates the computer software into the context of the total reading program.

\section{YORK FIELD TEST RESULTS}

\author{
DATE OF EVALUATION: February - March 1986 \\ EQUIPMENT USED: Apple lle \\ EVALUATOR: P.T. \\ TITLE: The Puzzler
}

\section{Comments}

The Puzzler was field-tested over a five week period in a Grade 4 class of 28 students. With two computers in use in the far corners of the classroom, the children worked in pairs on a rotation schedule. Each pair of students had access to the program for 25 minutes per day. The majority of students had two years previous experience on microcomputers, although this was the first reading program they had encountered. The Puzzler was used as a challenge and supplement to the regular reading curriculum.

The five stories, of increasing length and difficulty, generated a high interest level in these nine and ten year-old children. Three of the five selections were written in the first person, and two were animal stories. Students commented that the stories were imaginative and challenging. The children were able to read to the end of a particular story and complete the predicting and confirming tasks without losing interest.

The program promoted a spirit of cooperation rather than competition between the students. There was a good deal of interactive language as they

Continued on next page. 


\section{Figure 2, continued. Sample Panel Evaluation and Field Test Report.}

made predictions and analysed their choices. However, it was observed that towards the end of the test period, once the children had read the five selections several times and were familiar with the stories, they were not eager to the program. Perhaps there could have been more stories on the disk.

In terms of technical adequacy, the key commands were satisfactory and straight forward, although not elaborate (Arrow keys, S for Story, P for Prediction, etc.). However, the Escape option did not always work, leaving the reader with little flexibility in skipping ahead or backwards to other selections. Similarly, access to the menu was limited, and students wished they had more control over the software than simple page turning.

The teaching strategies outlined in the written documentation proved to be extremely helpful in introducing The Puzzlerto the class. Using an overhead projector, two sample stories "Petoskeys" and "The were read by the group. Predictions were made based on contextual clues, with students being given an opportunity to discuss and modify their choices. These two sample lessons prepared the students to read carefully and not be anxious about finding a 'correct' answer.

As an extension to this reading program, a group of seven students were motivated to compose their own open-ended stories. These were written individually and in pairs, both in longhand and on a word processor. The stories were read and discussed by their peers. This language arts component of the reading program showed that the students had understood the principles underlying The Puzzler and were able to assimilate them in a creative way.

As the documentation states, the children's transfer of predicting and confirming strategies to their daily reading is proof of the value of the experiences they received from The Puzzler. This transfer of skills was observed in daily reading assignments where students stayed on task a little longer than expected, despite difficult vocabulary levels. Students' comments were that The Puzzler "helps you learn," "gets you thinking hard," "keeps you reading until you figure it out," and "is fun once you know the story."

As well as confirming (or occasionally disputing) the panel's analysis, the field

field report highlighted some minor limitations in the design of the program that limited users' access to the program's menu. It noted that the addition of more stories to the disk could extend the utility of the package. In addition, the report offered a useful illustration of the ways in which the program activities could be effectively transferred to off-computer tasks in ways that would reinforce and extend the students' new learnings. And finally, it reported some evidence for the students' transfer of newly-mastered skills to other domains.

The panel and field evaluations were as likely to agree that a program was of high quality as they were to agree that a package was mediocre or inadequate. There was no evidence of a ceiling or floor effect in the rating levels for either type of evaluation. However, when the two forms of evaluation differed in their assessment of a package, 
it was usually the panel report that was more critical of the software.

There were ten packages over which there were major differences between the two evaluations about the software's quality. In each case, it was the evaluation panel that felt the package to be inadequate, while the field test report rated the package highly. Our analysis of the qualitative data indicated several reasons for this phenomenon.

First, and most importantly, there were several instances in which a teacher using the package in the field test modified or structured its use in a manner not suggested in the program's documentation, with the result being that the software was used to much better effect. These new patterns of use had not been anticipated by the panel, which had worked under the assumption that the programs would be employed in a straightforward, 'plain-vanilla' fashion, and had evaluated them on that basis. The evaluation and field testing of Tales of Adventure exemplify this pattern of discrepancy. (Students using this story program choose which of several directions they wish the plot to take at different points in a tale.) The panel evaluators rated this program as 'deficient' in all categories, and commented that the storylines were simplistic and unrealistic and that the software generally lacked usable content. However, the teacher was able to overcome the program's apparent limitations by integrating it into a structured lesson, which included a number of program-related activities:

We went through the first few screens as a group to help children get started. Pupils were then divided into groups of four. Each group kept track of the different paths they took on index cards. After each group had 'experienced' the program at least once, the class as a whole was introduced to flowcharts. They learned the three types of symbols used in flowcharts. Next each group was asked to flowchart parts of the stories on the disk on chart paper. The next step was for each group to create their own adventure. This was first done on chart paper. The flowchart was then developed into pages that eventually were published as books.

The field tester found the outcomes of this structured approach to use to be favourable:

Tales of Adventure is an attractive program. It can be a springboard for stimulating conversation, language development and social interaction. Children in higher grades effectively tutored those in lower grades in its use. Language was used to direct, report, predict, hypothesize and imagine.

A similar pattern can be seen in the evaluations of the program All About Dinosaurs. The panel considered this program deficient in content and instructional design, noting that-with the exception of a branching story section -the material was presented in a tutorial-quiz format more appropriate to a book. While the field evaluator agreed that the tutorial material was generally inadequate and made little use of the computer's features, she was able to make effective use of the branching story part of the program, but only by structuring the activity carefully: "Timely intervention by the teacher in encouraging the prediction and discussion of possible outcomes for each situation led to higher order thinking and problem-solving by the students. If this 
intervention did not occur, student choices were often made randomly with little discussion or verbal input."

In a few instances, a program that had been given a low rating by the panel was used with apparent effectiveness by students with special needs. For example, Alphabet Z0o, a program designed to enhance letter recognition and improve spelling, was found to be beneficial for children having specific difficulties:

This program proved to be especially effective when a more able student was paired with one experiencing difficulty with letter recognition. -The program provided opportunities for oral discussion as the children attempted to guess what picture was being drawn by the computer ... . If students are unsure of the letter name they are assisted by their partners.

In addition, an autistic child found the program to be highly interesting. He was able to identify many pictures independently and repeat the letters as they were articulated by a learning aide.

Panelists' disagreement with the underlying educational philosophy of a program (as inferred from the program's design) was another reason for the divergence in ratings between the panel and field reports. It resulted in the panels downgrading three packages. The Game Show was rated as 'deficient' in content and instruction by the panelists, who stated that "the program is very limited in its view of knowledge, and focuses on one-word answers without encouraging much student thought." The teacher who conducted the field testing had a different view: "This program can be used effectively to build vocabulary, reinforce spelling skills, and provide opportunities for verbalization, cooperation, and teamwork." It is clear that she had a different perspective on what pedagogical goals the program was meant to serve, and in her view it met those goals well. Comprehension Power, given a minimally acceptable rating in all four categories by panel evaluators, was also downgraded for its theoretical inadequacies: "A simplistic view of comprehension underlies this program. Students focus on selecting a right answer rather than developing personal understanding." The teacher conducting the field test, however, noted that the students felt the program offered a far superior alternative to paper and pencil testing of comprehension. The students were challenged by the program, and the teacher felt no conflict between her own educational style and that offered in the program; in fact, she indicated that it integrated very well into the curriculum.

Four other programs considered effective by field testers were heavily criticized by the panels for their overly simple design. In their comments the panelists noted a lack of appropriate feedback to the child, the simplistic forms of response allowed, and the limited range of the programs. However, the field trials suggested that even with these flaws the software still interested students, and could effectively facilitate learning and problem solving.

Surprisingly or not, depending upon one's perspective, panelists occasionally experienced difficulty in using a piece of software that young children found relatively easy to use, and this was another source of divergence in program ratings. In reviewing Turtle Power, a Logo subset for young children, the panelists noted several operational 
limitations (such as the need to save and load program subroutines separately) that were considered likely to inhibit effective use of the program. However, the field test report indicated that children could use the package efficiently, and that no technical problems were noted. Similarly, the panel evaluating Gertrude's Secrets commented that they had some difficulty in learning to operate the program and that children may require extensive support from the teacher in order to be able to do so. The field tester found, however, that even pre-readers were able to learn how to solve the puzzles simply by looking into the sample puzzle rooms.

In the case of a few other packages, panelists were more critical than field testers of the quality of the program documentation and/or the legibility of screen text and graphics. (It should be noted, though, that for several other programs, panelists were able to accurately anticipate the degree of difficulty users would have with software and documentation.)

For seven pairs of evaluations, what we have termed 'partial agreement' was found between the two forms of assessment. This level of agreement was defined as occurring when one of the evaluations considered the software under review to be mediocre (because of either several minor or one major weakness) while the other reported it to be either very desirable or not worth using. In three of these instances, field evaluators were more critical of the software than the panelists. The field testers cited technical problems with program operation, or noted a lack of student interest in the program.

As noted previously, the field tests often provided information that significantly supplemented that obtained from the panel evaluations. In several instances the field reports indicated that programs were used effectively as a means to promote cooperative problem-solving and the development of communicative and social skills. These outcomes were not always anticipated by the panel evaluators.

The reports usually provided other supplementary information of significance. The levels of interest generated by a program and whether these were sustained over time would be discussed. Field reports often indicated that students enjoyed using a program more when they had a greater choice in their strategies and more control over the computer. And they sometimes highlighted ways of integrating the software into the curriculum that did not occur to the panelists. On a few occasions the field evaluations broke new ground by pointing to parts of the program where better remediation or online help were necessary. And in two trials, the field testing indicated that the software might be more appropriate for a different age range.

\section{CONCLUSION}

The results of the comparative analysis suggest that, where possible, field tests of software should be undertaken to supplement other forms of evaluation. Field tests, by providing additional data on which to base evaluative judgement, can serve to increase the utility of the evaluation report in a number of ways. Classroom observation can bring to light technical and design limitations in software that may not be apparent to adult users. Conversely, operational difficulties foreseen by adult evaluators may prove to be minimal for certain student groups. A broader range of educational perspectives 
and philosophies can be brought to bear in the assessment of a program's value, including the students'. Field reports, by presenting the educational contexts in which software is used, can illustrate creative and effective strategies for program use and for its integration into the curriculum in ways that might not have been anticipated by evaluators, resulting in a greater appreciation of the program's potential. Field tests may also give a clearer indication of the suitability of a program for meeting certain specialized student needs.

This is not to argue that software evaluations that lack a field component have no value, however. The overall level of agreement found between the panel and field tests in the present study suggest that systematically conducted panel evaluations will usually be able to assess a program's quality with reasonable accuracy. Our findings do indicate that evaluators need to be sensitive to a wide range of contexts and strategies for a program's possible use if they are to do it justice in their assessment. But the ease with which simple field evaluations (of the type employed in the present study) can be implemented, and the value of the information to be gained, argues strongly for undertaking field testing as a part of software evaluation far more frequently than is presently the case.

\section{REFERENCES}

Alberta Education. (1986). Computer courseware evaluations: June, 1985 to March, 1986. Edmonton, AB: author.

Dudley-Marling, C., Owston, R. D., \& Searle, D. (1986, October). Guidelines for the field testing of microcomputer software (York/IBM Cooperative Project Document No. 5). North York, ON: York University Faculty of Education.

Diederich, B. (1974). Measuring growth in English. Urbana, IL: National Council of Teachers of English.

Eisner, E. W. (1979). The educational imagination. New York: Macmillan.

EPIE Institute. (1986). The educational software selector. New York: Columbia Teachers College Press.

Glaser, B. G., \& Strauss, A. L. (1967). The discovery of grounded theory. Chicago: Aldine.

Guba, E. G., \& Lincoln, Y. S. (1981). Effective evaluation. San Francisco: Jossey-Bass.

International Council for Computers in Education. (1984). Evaluator's guide for microcomputer-based instructional packages. Eugene, OR: University of Oregon.

Muller, E. W. (1985). Application of experimental and quasi-experimental research designs to educational software evaluation. Educational Technology, 25(10), 2731.

National Council of Teachers of Mathematics. (1984). Guidelines for evaluating computerized instructional materials (rev. ed.). Reston, VA: author.

New Brunswick Department of Education. (1974). Manual for interviewers of French. Princeton, NJ: The Educational Testing Service.

Owston, R. D. (1985, December). Software evaluation using YESES. Paper presented at the annual conference of the Ontario Educational Research Association, Toronto. 
Owston, R. D. (1987). Software evaluation: A criterion-based approach. Scarborough, ON: Prentice-Hall.

Owston, R. D., \& Dudley-Marling, C. (1986, April). A criterion based approach to software evaluation. Paper presented at the annual meeting of the American Educational Research Association, San Francisco.

Pike, R. (1983). Evaluating the effectiveness of lessonware prototypes: Some guidelines for use in the development of educational software. Toronto: Ontario Ministry of Education.

Popham, W. J. (1978). Criterion-referenced measurement. Englewood Cliffs, NJ: Prentice-Hall.

Preece, J., \& Jones, A. (1985). Training teachers to select educational software: Results of a formative evaluation of an Open University pack. British Journal of Educational Technology, 16(1), 9-20.

Ragsdale, R. G. (1982). Evaluation of microcomputer courseware. Toronto: OISE Press.

Signer, B. (1983). How do teacher and student evaluations of CAI compare? The Computing Teacher, 11(2), 34-36.

Smith, D., \& Keep, R. (1986). Children's opinions of educational software. Educational Research, 28(2), 83-88.

Tovar, M., \& Barker, N. (1986). Field test evaluation of educational software: A description of one approach. Canadian Journal of Educational Communication, 15(3), 177-190.

Truett, C., \& Ho, C. (1986). Is educational software fieldtested? The Computing Teacher, 14(2), 24-25.

Tyler, R. W. (1950). Basic principles of curriculum and instruction. Chicago: University of Chicago Press. 


\section{The Integration of Educational Technology in the University}

\section{Diana R. Carl}

\begin{tabular}{l} 
Abstract: The research literature in educational technology contains very little infor- \\
mation on how university faculty respond to new technologies for the purpose of integrating \\
them into their teaching responsibilities. Since the role of technology in the university is \\
taking on increased importance in terms of student access and preparation in the employ- \\
ment of technologies, the use of such instructional innovations in university teaching \\
becomes increasingly important. This paper examines the literature regarding the imple- \\
mentation of instructional innovations within the university and works toward a clearer \\
definition of how instructional innovation takes place in universities. The paper concludes \\
that faculty are key decision-makers in the implementation process and that the discipline \\
of the faculty member appears to be influential in this decision process. \\
\hline
\end{tabular}

\section{INTRODUCTION}

As early as 1972 the Carnegie Commission recognized the importance of integrating educational technologies into higher education (cited in Carr, 1986). Many have called attention to the need for higher education to prepare to incorporate these technologies (e.g., Lielber, 1978; Boaz, 1982; Kelly \& Anandam, 1984; Carr, 1986; Wartgow, 1986). The challenge is to combine all types of education to make a superior quality of higher education using technology. Yet, over twenty years later, educational technologists still express much concern that faculty in higher education have not integrated these technologies with day-to-day teaching activities (e.g., Heinich, 1984; Shrock, 1985; Cannon, 1983; Liebler, 1978; Harrington, 1977). In a recent teleconference regarding the involvement of faculty in providing distance education, which uses many of these technologies, administrators expressed frustration in working with faculty to develop courses using distance technologies.

The frustration is apparently not one-sided. Holloway (1985) noted that faculty often express feelings of being 'at the mercy of' media units. Shrock (1985) documented the suspicions faculty and educational technologists had of each other, and the problems these suspicions caused in implementing technologies in higher education.

Diana $R_{1}$ Carl is an Instructional Designer with the Division of Continuing Education, The University of Manitoba, Winnipeg, MB R3T 2N2. 
Kelly and Anandam (1984) and Heinich (1984) state that these technologies are threatening to faculty in that the very structures by which teachers teach and students learn may undergo drastic changes. In total, barriers appear to exist which have prevented the integration of educational technologies into university teaching.

The research tradition of instructional technology appears to contain very little information on how non-technologists relate to instructional technologies including adoption/rejection patterns (Shrock, 1985). The purpose of this study is to review the literature regarding the integration of educational technology into higher education and to provide a clearer picture of what wC do and do not know about how to effectively integrate technologies into teaching in higher education.

Educational technology is defined as both a product and a process (Romiszowski, 1981). Products refer to the equipment used in the provision of education and cover a wide spectrum from chalkboards to communication satellites. Process refers to the software produced such as overhead transparencies, videotapes, audioteleconferences, and computer-assisted instruction. The process by which these are produced, usually called instructional development, is also considered educational technology.

Little distinction appears to have been made between processes and products, and between specific forms of technologies. Some of the literature refers to educational technologies as 'instructional innovations,' grouping different educational technologies (e.g., video and computer-based instruction), processes (e.g., instructional design, course team approach), and strategies (e.g., pcrsonalized system of instruction, competency-based instruction) together. It was difficult to separate and distinguish these for the purpose of analysis.

The focus of this paper is educational technology in the university. The terms educational technology, instructional development, and instructional innovation will be used interchangeably. The term higher education will refer to the traditional university structure. Some of the literature has referred to the integration of technologies into community colleges. Community colleges appear to have a slightly different organizational tradition and have used technologies more readily in the provision of instruction. (e.g., competency-based learning). In addition, the university differs from institutions providing primary and secondary education (Kozma, 1985; Baldridge, 1983; Meyer \& Rowan, 1983). These institutions differ from the university in many respects. Universities are more loosely-coupled than primary and secondary schools in defining the functions of their teachers. The amount of control exercised by clients of primary and secondary schools is greater than that found within the university. The governing structures differ as well. As will be demonstrated, thcsc factors appear to be related to the ways in which the organization responds to instructional innovation. Because primary and secondary schools and community colleges differ from universities with respect to these factors, comments made in this study do not extend to either of these sectors.

Much has been written about instructional innovation within some specific types of university programs such as teacher and medical education. While this appears useful in defining how innovation takes place within these disciplines, this literature is too narrowly focused to adequately address instructional innovation in the university organization as a whole. 
In this paper, the term administrator refers to those people in the university who have management functions and do not have teaching among their primary responsibilities. Department chairpersons appear to be a hybrid of administrator and teacher and, therefore, are not included in this category of administrator. Educational technologists are those individuals responsible for the development of instructional hardware and software in the university but who do not teach as part of their primary university responsibilities. These include audiovisual specialists, computer systems analysts and programmers, video production specialists, and instructional developers among others. The term faculty refers to those who have teaching, research, and community service as their primary responsibilities. For the purposes of this paper the term integration will mean the use of educational technologies in routine instruction for which faculty are responsible. Some of the literature distinguishes between instructional innovations and other kinds of innovations which may take place in the university (such as administrative or curricular innovations). There is reason to suspect that differences may exist in the ways in which integration takes place for different types of innovations. Therefore, this study will be confined to the study of instructional innovations.

\section{FACTORS RELATED TO NON-INTEGRATION}

Various reasons have been cited for the non-integration of educational technologies. The literature has generally consisted of observations made by either administmtors or educational technologists. As well, the integration problems in North American universities appear to exist in European and Australian universities (Cannon, 1983; Lallez, 1986; Jevons, 1984). In examining the literature, it was difficult to separate a potential causal agent from a symptom to get at the roots of the problem.

Cannon (1983) cited three reasons for the fact that after thirty years of recommendations for change in Australian universities it has not come about. They are: a) a failure to take into account the distinctive organizational pattern of the university; b) the characteristics and work patterns of faculty are not understood; and c) the forces to change teaching have been weak. In a survey to determine why faculty did not participate in teaching improvement programmes, many faculty indicated that good teaching was not rewarded in promotion and tenure decisions (Botman \& Gregor, 1984). Liebler (1978) also noted that there were very few incentives for faculty to involve themselves in instructional development procedures. Lallez (1986) noted that university structures themselves may contribute to the problem. They have a long-standing and rigid tradition which is resistant to changes in educational technologies.

Wartgow (1986) notes that the conflicting value systems of administrators and faculty may also be another factor in the lack of integration. Forsythe and Collins

in a report on the effect of new technologies on universities in British Columbia, noted that instructors involved in the course design process were not entirely happy with the great amounts of time and energy they expended in creating the instruction for an off-campus course using the technologies. The study recommended that faculty reassess their roles and adapt to the changes in learning which come about as a result of the presence of the new technology. In a study of the patterns of service to adult 
learners, which included course delivery using educational technologies, Harrington (1977) noted that faculty would rather not change their instruction. Yet, when scarce funds were diverted to technology ventures, faculty expressed resentment. He also notes that extension courses which used technological delivery systems were met with stiff opposition but those which used faculty presented no problems. Faculty wanted such technology-based services kept away from the academic structure; preferably in the extension division. Shrock (198.5) noted that faculty perceived instructional development procedures as lowering the standards of the course and of the university in general. Outright sabotage and knowledge-hoarding were cited as ways in which faculty have thwarted the integration of educational technologies (Shrock, 1985; Rogers, 1975; Kozma, 1985).

Kelly and Anandam (1984) were more sympathetic to the reticence of faculty to change the structures by which teachers teach and students learn. Habermas (1973) defends the slowness of faculty to adapt to changes and technologies. External forces can pressure the university to assume an advocacy position for a technology. The act of academic deliberation and slowness of the university and its faculty are defenses against external pressures to swiftly adopt a technology without sufficient attention to the consequences of the adoption.

The availability of resources may be a factor in the integration as well. In studies of the diffusion patterns of instructional innovations within universities, the response most given by faculty for not adopting an educational technology was lack of resources (Kozma, 1985; Rogers, 1975). Although it has been suggested that the complexity of the technology may be a factor in its adoption, few authors treated this factor. Rogers (1975) suggests that other factors related to the specific technology may be more important in determining whether and how it becomes integrated into the university.

\section{STUDIES IN THE INTEGRATION OF EDUCATIONAL TECHNOLOGY}

Many have treated the integration of educational technology into higher education as a change problem. While the literature is filled with descriptions of the ways in which the university differs from other types of organizations and what this means in terms of initiating change in higher education, few research studies have documented how instructional innovation occurs in the university.

Rogers (1975) conducted the most comprehensive study found. He defined innovation as, "an idea, practice, or product perceived as new by the individual or some other adopting unit" (p. 17). The innovations were considered tracers whose diffusion into the university could be traced to illuminate the change process. The purpose of the study was to determine how four instructional innovations diffuse to and are adopted by university professors. Rogers provided an outline of the underlying theory of diffusion and adoption first presented in The Communication of lnnovation (for a complete description of this theory see Rogers \& Shoemaker, 1971). There were three key populations from which data were solicited: requesters of information on IMPACT, secondary receivers of information, and tertiary receivers of information on the same 
project. The innovations were sponsored by a major grant institution and were publicized to personnel in institutions of higher education who could apply to take part in the innovation project of their choice. The study used questionnaires and interviews to obtain information from 2,921 individuals who had requested information on IMPACT. Standard follow-up procedures were employed, and non-response was discussed in both the procedures and the results. Results were analyzed by the type of respondent.

Of the requestors of information, 57\% were administrators and $43 \%$ were faculty, the majority of both groups holding doctorates. Over half first learned about the project through the brochure which described the projects (54\%). Diffusion to secondary receivers was more difficult to isolate using the data gathering techniques employed. Most secondary receivers were located in the same department in which the requestor resided. Those secondary receivers who adopted the innovation talked more with their colleagues about the innovation than did non-adopters. Personal discussion was by far the most pervasive form of diffusion activity engaged in by adopters. But secondary receivers did not normally hear about the innovation from requestors. Only $21 \%$ of the secondary receivers indicated that the requestor was the first source of the IMPACT information. More often they first learned of the innovation from the brochure (40\%). Conversations between requestors and secondary receivers were casual, and over half said the conversations regarding the innovation were informational rather than persuasive in nature. There was little effort by the requestor to encourage the secondary receiver to adopt the innovation. Only $6 \%$ of the secondary receivers adopted the innovation. Those secondary receivers who adopted differ horn other secondary receivers who did not adopt in that they were: a) more likely to take on more than one IMPACT innovation; b) had shorter tenure at the university; c) showed greater innovation in using teaching methods; d) were slightly older; e) held more doctorates; 1) consisted of more administrators; g) were in universities in which there were greater rewards for teaching; h) were in institutions with smaller enrollments; and i) were slightly higher on the Gorman Scale for rating universities on academic achievement. Secondary receivers and requestors were similar with respect to personal and institutional characteristics as well as discipline. Secondary receivers talked to tertiary receivers $38 \%$ of the time and normally were in the same department as the requestors and secondary receivers.

Rogers had suspected that the complexity of the innovation (in this case, computers) would be a barrier to diffusion. However, lack of diffusion does not appear to be related to lack of experience with the computer but with other related factors (e.g., programming languages, processes employed, administrative support). Some evidence was found to support lack of compatibility with existing computer systems to be a factor. Rogers summarized the apparent resistances and barriers to diffusion as being: a) lack of funds; b) lack of time; and c) lack of trained personnel.

Using Rogers' (1975) study as a basis and examining IMPACT and LOCI innovations, Kozma (1985) described the way in which faculty become aware of new ideas and technologies in teaching, and decide whether to adopt/disseminate them further into the institution. He identified four different frameworks commonly used to examine innovation: a) complex organization framework - the decision to innovate is made by those in positions of authority in response to external pressures; b) conflict framework 
- different groups within the system hold diffcrent interests which are resolved through a confrontational process; c) diffusion model - the presence of an innovation in the system starts the change process and the rate of its diffusion into the system depends on the characteristics of the adopters and of the innovation; and (d) planned change - a plan for change is developed by a change agent (opinion leaders are central to the process because of the influence they have on others in their system), and change is reached through interpersonal processes to facilitate communication, joint decisionmaking, and to reduce tension and conflict within groups. Kozma used theoretical sampling to determine whether the dam supported any parts of these frameworks.

Twenty-six cases which received IMPACT or LOCI support were analyzed. Data were collected using field and telephone interviews with 145 persons in 28 institutions, and examining institutional catalogs, project proposals, reports, and other documents. Kozma reached a number of conclusions.

a) Innovation is evolutionary - new instructional practices are built on past practices and experiences of instructors, and with familiarity with similar innovations. A corollary is that innovations which were adopted appear to be alternative expressions of attitudes, values, preferences, and philosophies embedded in previously used techniques.

b) Innovation is not easily distinguishable from previous practices unless pronounced resources are needed. Innovations were rarely implemented in addition to the faculty member's regular activities.

c) Adopters appear to fall into two categories - personal and collaborative;

d) Most innovations were the result of personal decisions on the part of the faculty member - 'individual adoptions'. These people tended to be relatively isolated and did not have positions of organizational responsibility nor extended interpersonal networks within the organization.

e) For most cases, the decision to adopt was personal. Reasons for individual adoption of an innovation are egocentric and relate to personal rather than institutional concerns.

f) Individual adopters did not fare well with the innovation after external funding was withdrawn.

g) Collaborative adopters differed from personal adopters in that they involved others in their decision.

h) The motivation for collaborative adopters is an identified need in the group or organization.

i) In its dominant form, instructional innovation is an internal process of personal or professional development.

j) Instructional improvement centres can play a part in the innovation process.

Kozma also made two observations regarding innovations, faculty, and the university organization. The university organization in its present form elevates the personal motivations and attitudes of faculty members and decreases the importance of organizational needs for innovation. Further, teaching and accountability are not normally linked. He concludes that more institutionalization is needed for increasing innovation. 
However, the call for instructional improvement centres and more institutionalization did not appear to have grounding in the data presented in his paper. Kozma concluded that these results invalidate some change frameworks. The planned change framework appears not to take into account the ways in which faculty members decide to alter their teaching. Rather the adoption process appears to be one of the teacher matching the components of the innovation with similar, previous teaching practices. In addition, a conflict model of change does not appear to go along with the types of collaboration described by respondents in the study. No cases of resistance to innovation were found among the participants.

The studies of both Kozma and Rogers contain the most comprehensive data found regarding the integration of educational technology into the university. The purposes of these studies are admittedly to describe how an innovation is naturally diffused throughout the university. Since faculty who did not receive information on these innovations were not studied, the question arises as to whether these findings represent the way in which most faculty respond to the change process.

Shrock (1985) conducted a naturalistic study for the purpose of gaining information as to how non-technologists view instructional technologists and the instructional innovations they espouse. The study took place at an unidentified university which had acquired federal funding to convert its curriculum to a competency-based form of instruction. Data were collected through observations of workshop presentations, structured interviews with workshop participants and with workshop consultants, and examination of participants' products, records of participants and workshops, and grant correspondence files, (through unstructured interviews with grant administrators and instructional development personnel, and informal observation and conversations).

As this was a naturalistic study, certain themes began to emerge as the data were collected. Many faculty were in the program only for the monetary stipend paid and had no intention of using the materials in their classes. Faculty viewed the grant administrators as outsiders and resented the intrusion of the grant personnel into how they conducted classes. Grant personnel regarded many of the faculty as lazy and inflexible. Great amounts of hostility were present between the grant administrators and the faculty, and instructional development was associated with other environmental stressors (cutbacks and faculty layoffs). Faculty expressed resentment towards the 'lavish' funding the instructional development program received and the power it gave grant administrators. Grant administrators considered the lack of facility with instructional development to be an informational rather than an attitudinal problem and based their strategies on this assumption. They appeared to neglect the role of affect in the adoption of innovations, and offended faculty. A substantial number of the faculty rejected instructional development and instructional technology. Shrock notes that the results were different for different faculty members but does not elaborate on these differences. She limits the generalizability of her study since it is naturalistic, but her data paint a picture of faculty as a powerful force in the change process.

Liebler (1978) surveyed the utilization of instructional development in higher education in the United States. Chief academic officers of universities in several selected states were requested to indicate if their institutions used an instructional development process. One hundred and thirty institutions (81\%) replied of which 38 
indicated initially that they did not use instructional development procedures. Followup telephone interviews with these 38 resulted in changed answers, which indicated to the researcher that there may be a lack of understanding on the part of the chief academic officer regarding the functions of instructional developers. Only 15 institutions indicated that they used a complete model of instructional development. Responses indicated that very few faculty members were involved in the process, and little incentive was offered to faculty for their involvement in the instructional development process. Most institutions still follow a traditional pattern of audiovisual and curriculum planning in which aids and materials arc developed after the lessons have been planned. Since faculty are considered central to the instructional development process, the author expressed concern that after ten years of work to integrate it into universities so few were involved with the innovation. He concludes that key administrators must support instructional development if it is to become an integral part of the university. However, this conclusion does not appear to be substantiated in his data.

Botman and Gregor (1984) addressed instructional development in teaching improvement programs. They used a variety of data collection techniques to develop a picture of faculty participation in these programs. The respondents indicated that good teaching was not rewarded in promotion and tenure decisions as much as was research. In communicating the workshops to other faculty, word of mouth was considered the most effective means. The findings indicated that faculty in different disciplines held consistently different views of teaching. The authors also noted that if attitudes toward teaching are discipline-specific, then it is reasonable to assume that heads of units will reflect the attitude espoused by the discipline. If heads of units are used as change agents, this may present difficulties for the change process.

In a case study documenting the introduction of satellite technology into higher education in British Columbia for the purpose of providing distance education, Forsythe and Collins (1983) presented the models employed for course development and described the processes and institutional involvement. The study dealt with the interaction of institutions and faculty with satellite technology and with the 'systems approach' (instructional development) used to develop courseware. Data were collected using interviews with senior administrators concerned with distance education. Information was obtained regarding faculty involvement but it is not clear from the report how this information was obtained. Although the instructors agreed that the produced course was much superior to the traditional offering on campus, they were not entirely happy with the great amounts of time and energy they were required to expend in creating the instruction for an off-campus course using the technologies. The project used a 'course team' approach which differs from the ways in which faculty personally design their courses in that they work with a team of experts. This procedure may have influenced the responses of the faculty to the technology and systems approach.

Many researchers appear to regard instructional development procedures as innovations which offer faculty more effective organizing procedures for their instruction. There is also the assumption that faculty do not engage in these procedures. Kerr (1981) questioned this view and studied the ways in which teachers design their instruction. He notes that teachers normally have no formal training in instructional development procedures and find it difficult to use these procedures when asked to do 
so. This does not mean that teachers do not have an approach to designing their materials. Rather, they have their own ways of proceeding although these vary greatly between teachers. He refers to their efforts as 'naturalistic design procedures.'

In total, the studies which have been done to date about the integration of educational technology into the university seem to agree that: a) integration efforts have not been very successful; b) faculty individually and collectively appear to be autonomous; c) rewards provided by the university do not appear to encourage faculty to become involved with educational technology on an on-going basis; and d) faculty themselves appear to be the primary decision-makers regarding the integration of technologies into their instruction. Several concluded that more support for change is needed from administrative levels and that strategies employed for integration should include teaching improvement centres. As will be demonstrated, administrative support and teaching improvement programmes may not be as effective as one might think. The ways in which faculty think and act may diminish the value of these approaches for the integration of educational technology.

\section{THE ROLE OF FACULTY IN INTEGRATION}

Much of the literature found regarding university faculty reinforce the conclusion that faculty respond more to their own initiatives to change than to administrative initiatives. Ikenberry (1972) noted that the decentralized nature of the academic enterprise affords faculty significant power. The university is characterized by the institutionalization of discipline differences and a weak system of coordination of these disciplines. These differences are highlighted and supported in the university; integration is not emphasized (Lane, 1985). Rugg, Warren, and Carpenter (1981) studied faculty orientation toward goals of the university using the Institutional Goals Inventory. The results demonstrated differences along the lines of discipline. Unity across all faculty was found regarding the importance of the teaching and research functions and the importance of sufficient economic support to attract and keep qualified faculty. On most other points faculty differed, including their perception of the importance of nontraditional education (off-campus learning). Education faculty were more predisposed to this goal than were faculty in business, arts, humanities, science, and mathematics.

Kozma (1985) noted that the university organization in its present form elevates the personal motivations and attitudes of faculty members and decreases the importance of organizational needs for innovation. Further, teaching and accountability are not normally linked in the university. Cannon (1983) stated that the university cannot be examined as a monolithic structure which will respond uniformly to change but must be approached as a heterogeneous organization. Because faculty are strongly allied to their disciplines, "the relationship between individuals, departments, and faculties in other universities is often more important, stronger, and more active than intra-university relationships" (p. 23). Faculty may identify more with goals expressed by others in their own discipline in other universities and less with the goals articulated by the university in which they are employed This point is almost always overlooked by change agents in universities. 
Clark (1983) refers to this system as an 'organized anarchy'. The working and relating patterns of academics in a given discipline are constructed and arranged by the academics themselves rather than by forces external to the discipline. Change flows within a discipline and through individual works it permeates the discipline. Thus, the discipline appears to be the unit which both resists change as well as generates change. Faculty in one discipline do not normally interfere with changes in another discipline in the same university. Units can independently prosper or die. The means for change, then, are found within this 'understructure' of the university rather than at the upper orgauizational levels. Clark notes, however, that while the balance of power may appear to consistently reside within the understructure, external forces to the university may at times shift this balance in favour of the upper levels. Declining enrollments and decreased economic supports may be seen as forces which shift the power to initiate change to upper, more centralized levels. It may be that under such conditions faculty will respond more readily to change initiated at administrative levels.

The way in which faculty members perceive their roles as teachers and the privacy they attach to their teaching may influence their openness to instructional innovations. Rogers (1975) noted that the faculty member's need to be a lecturer is negatively related to being an adopter of the innovation. As previously noted, faculty in Shrock's (1985) study resented the intrusion of grant personnel into their classrooms. What occurs in the individual classroom is considered private by many faculty, and decisions about what will occur are considered individual and private It would appear that the university coordinating structure has little influence on the way in which faculty elect to design courses (Dowdeswell \& Good, 1982).

The observations of Kozma (1985) and Rogers (1975) reinforce the conclusion that the discipline appears to be a meaningful unit for the faculty member in the change process. Faculty in both studies appeared to have more contact with others in their discipline than with other faculty. Not surprisingly, they also have more contacts with other faculty than with administrative staff (Cannon, 1983). Shrock (1985) also noted discipline differences in passing. In total, it would appear that faculty: a) have more autonomy in their work as afforded by the way in which the university is structured; b) engage in communications with others in their discipline much more than they do with those outside of the discipline; and c) hold similar values to other faculty in their discipline with regard to teaching, research, goals, and standards. The discipline of the faculty member appears to be a stronger influence on their thoughts and actions than is the university structure, and instructional innovation appears to be a matter of personal choice influenced by the discipline rather than the university. This suggests that if a fuller integration of educational technology is to be achieved in higher education, efforts should focus on the individual faculty member and the discipline. A strategy of global integration into the organization may not be appropriate for a university.

\section{FACTORS RELATED TO THE TECHNOLOGY}

The characteristics of the innovation may also help to explain why some educational technologies are adopted and others rejected. Fewer researchers treated this 
variable although common sense would indicate that the interaction of the innovation with the client would be a factor worthy of attention. It is important to assess an innovation in terms of its: a) relative advantage; b) compatibility; c) complexity; d) trialability; and e) observability (Rogers, 1975). Kelly and Anandam (1984) note that various technology vendors will use 'haphazard, piecemeal, and erratic' means of making a sale to the university, and these might not necessarily be compatible with the existing organizational needs. The development of a technology in the university must be considered evolutionary. As well, human needs should have preeminence, and technologies should not be imposed. Rogers (1975) noted that little modification of the innovation appears to take place once it is adopted, which does appears to be related to differences in disciplines. There seems to be a relationship between the discipline of the inventor and that of the requestor in the decision to adopt. Again, this reinforces the lines of discipline as being a major factor in the adoption of a technology. If the innovation was developed within the discipline, others in the discipline might be expected to adopt it. The perceived relative advantage of the innovation is related to its rate of adoption. Rogers concluded that the compatibility of the innovation with existing beliefs and practices was not a factor in the decision to adopt. However, Kozma (1985) found a relationship.

As faculty hold value systems which may differ from those of university administrators, Kelly and Anandam (1984) caution that the cost-effectiveness of a technology should be weighed from several different viewpoints before identifying this as a relative advantage in adopting it. Cost-effectiveness is a subjective concept with different interpretations. An administrator's definition of cost-effectiveness may threaten the teaching and research values held by faculty members and create conflict situations.

Technologies are never adopted alone but are accompanied by 'systemic effects'. That is, the presence of the technology in the university may result in a change in organization of the university's resources and functions. Lallez (1986) noted that when one adopts an innovation, one also adopts the culture of the innovation. They bring with them an entire interrelated set of life-cycles, standards of conduct, interpersonal relationships, social representations, images of the world, views of life, and a plethora of ambitions and desires. The culture of the innovation consists of those administrative and resource structures and practices which are associated with the innovation. The course team approach is an example of an innovation culture. It is not a physical part of other technologies but has been extensively accepted as the method by which software should be developed. Other examples of innovation culture are found in the divisions of personnel in computer service units and in television production centres. Changes in the balance of power are often a part of this as well, as noted by Shrock (1985) and others. Service units responsible for a technology may become vested with power and resources which generate the feelings of frustration described by Holloway (1985) and result in new power relationships and games. Wartgow (1986), in discussing obstacles to non-traditional learning, notes administrators might be better off spending time analyzing the symbolism and perceptions of various decisions related to non-classroom learning and in assessing the relative compatibility of the particular activity with the 'culture' of the institution than dealing with straight cost-effectiveness calculations. 
Forsythe and Collins (1983) address the university culture/innovation culture interaction in their recommendation: "The coming of the new technology presents new challenges for educators and changes the nature of their task. There is a need for educators to reassess and redefine their roles, to be open to adaptation, and, to, themselves, be prepared to learn" (p. 43). "There needs to be increased co-operation amongst educators, instructional designers and media producers; a willingness to share knowledge and expertise and an openness to learning" (p. 46). Their recommendation is that the university culture change to incorporate the culture of the innovation. Smith, Daniel, and Snowden (1984) were also describing the university culture/innovation culture discrepancy when they noted that while traditional academia is informal and collegial, distance education is highly centralized and requires a more directive style.

As important as the interaction of the innovation culture with the university culture is the interaction of the innovation culture with the student culture. Students have learned to learn in certain ways which the technology may alter. The effects of this interaction on students is important in making the decision to innovate. In judging a technology, then, Lallez suggests that "its significance does not lie in its technical features and one cannot appreciate and judge its cultural consequences from that point of view" (p. 188).

Earlier in this paper the impact of the discipline was treated as an important factor in the decision to integrate technology. As each discipline has its own set of values for teaching and research, it can be argued that each discipline has the potential of forming a separate culture within the university culture. Lallez's suggestion that the compatibility of the technology culture with the university culture be examined may extend to disciplines as well. Those elements which compose the technology culture may merit examination in terms of its compatibility with the discipline culture.

\section{RESOURCE ALLOCATION FOR INTEGRATION}

As the innovation has a potential effect on the culture of the university, it has a more obvious effect on the allocation of resources within the university. Lallez (1986) notes that one reason to employ these technologies is to compensate for shortage of material, financial, and human resources. He refers to the integration of technology as being an 'educational capital gain,' which can have an effect on the internal resource structure of the university as well as on the external resource relationships. It is rare for a technology to be completely under the control of the organization of which it becomes a part. There are always spare parts or additional pieces or new relationships formed with external bodies for the purpose of fostering the technology. Technologies, then, might be viewed as perpetuating a capital-intensive rather than labour-intensive resourcing plan. Wartgow (1986) recommends that administrators not become lost in the accounting and budgeting for innovations but rather maintain a perspective that recognizes educational technology within the larger context of academic program development. Williams (1966) also cautioned that too much central budget control can hinder innovation. Kelly and Anandam (1984) recommended giving people who experiment with the innovation full monetary and moral support through failures and 
through successes to enable them to identify how the innovation might work best in the university.

Kozma (1985) stated that lack of resources was the primary reason given by faculty for not adopting an innovation. He also noted that individual adopters did not fare well after external funding was withdrawn. This obviously demonstrates a need for on-going resource support for an innovation. The question arises as to how much alteration of resource allocation patterns is acceptable in the name of innovation.

Hackman (1985) observed that investment of resources into separate service units (such as television production centres, computer services, audiovisual centres) may be detrimental to the existence of the unit. She distinguished between core and peripheral units in the university. Core units are defined as those whose functions are central to the mission of the institution. Academic departments engaged in teaching and research are examples of core units. Peripheral units arc non-central and often include the administrative and support services of the university. Core units appear to be more stable. She noted that peripheral units become regarded as optional and are vulnerable in that they are the first to be cut back when funding becomes scarce. Separate service units for educational technology can and have suffered this fate in a number of institutions.

Taken together, the observations of Hackman (1985), Wartgow (1986), Williams (1966), Kelly and Anandam (1984), and Kozma (1985) build a case for flexibility in resource allocation with more authority for resourcing vested in the substructure. If core units are more stable as Hackman observes, then it may be appropriate to consider a resource allocation plan for educational technology which would facilitate the development of the technology within core units rather than setting up a separate costcentre. This might encourage experimentation and adaptation to individual and discipline-related teaching values.

\section{DISCUSSION}

There is wide agreement that the university structure differs from other formal organizations in the amount of autonomous decision-making granted to faculty and disciplines. A great deal of support was found for the conclusion that decision-making for instruction rests with the individual faculty member rather than with departmental or other administrative levels of the university. Therefore, the decision to integrate technologies into higher education appears to rest with individual faculty.

Values held by individual faculty appear to be strong determinants of adoption patterns. Several sources indicate that the beliefs and previous experience of the faculty member strongly influence the decision to use a new technology in teaching. The discipline of the faculty member appears to be the significant unit of influence on faculty teaching and research values. Academic standards, teaching practices including acceptable technologies, and rewards in the form of acceptance by colleagues appear to be determined within the social structure of the discipline. Affiliation with the discipline appears to be stronger than affiliation with the university and extends into other universities. If opinion leaders of a group make a difference in the adoption of an innovation as Rogers (e.g., 1975) suggests, then it may be necessary to look beyond the 
immediate institution to identify opinion leaders for a given discipline and to work with them to initiate change.

The university's influence on teaching practices appears to be minimal due to the rewards it gives for teaching and due to the factors described above. But there are indications that this balance may shift in favour of the university when external pressure is applied (e.g., during times of economic hardship) (Clark, 1983; Rutherford, Fleming, \& Mathias, 1985). Given such circumstances, it is possible that faculty will be more receptive to technological changes originating at the administrative level of the university.

The characteristics of the educational technology appear to be important factors in the integration process. The more the technology is similar to and compatible with the beliefs and teaching experience of the faculty member, the greater likelihood that the technology will be adopted. This could explain why, when so many other new technologies have failed, microcomputer technology has enjoyed widespread acceptance by faculty. The compatibility of the technology with the teaching tradition of the discipline also appears important. It was noted that innovations developed within a discipline appear to be more readily adopted by others in that discipline.

It was pointed out that an innovation culture is adopted in addition to the innovation itself. In the process of integrating the technology the university may find itself integrating processes and relationships associated with the technology. A prime example of this is the course team approach to the design of instruction, which is not a part of the technology but is strongly associated with it. It would appear important to be aware of the discrepancies between the university, discipline, and technology cultures and to determine what kinds of compromise are appropriate to maintain meaningful value systems for higher education. Resourcing patterns for the technology may as well affect the integration of the technology. The decision to place technologies in separate service units may be immediately rewarding to the administrator but may inhibit integration and place the technology in vulnerable positions in the university. The empty television studios in universities are monuments to this tactic. Development of the technology within academic units may be a more sound approach to educational technology within the university.

Much of the literature specifically examined workshops and teaching improvement centres as strategies for change. These have met with mixed reaction from faculty. Shrock (1985) cautioned that the use of such strategies is based on the assumption that faculty will use the technology if they are provided the knowledge and skills to do so. This does not take into consideration other potential reasons for non-use such as attitudes and environmental problems. It appears probable that these other reasons may account for the lack of faculty involvement more than lack of skill and knowledge.

In total, it would appear that within the university prospects for integration of educational technology are limited if a global strategy alone is utilized. Strategies for integration should be formulated for each separate academic unit and take into account the value systems of the discipline.

It is obvious that much more work is needed to determine how the integration of educational technology into the university is best accomplished. A number of change models have been examined for use in higher education (e.g., Wartgow, 1986; Kozma, 
1985; Rutherford, Fleming, \& Mathias, 1985; Clark, 1983; Kelly \& Anandam, 1984; Swanson, 1983; Dill \& Friedman, 1979; Rogers, 1975; Bennis, 1976; Havelock \& Havelock, 1973; Rogers \& Shoemaker, 1971; Lippitt, Watson, \& Westley, 1958). While much has been written, it would appear that more systematic examination of the problem is warranted. There is a need to develop working hypotheses which can more accurately describe how educational technologies are integrated, and to more accurately describe how integration naturally takes place. Various models of change merit further systematic examination of their effect on the adoption of educational technologies within the university. The literature suggests definite directions for further research but more is needed before a paradigm for the integration of educational technology into the university can be more accurately described.

\section{REFERENCES}

Baldridge, J. V. (1975). Organizational innovation: Individual, structural and environmental impacts. In J. V. Baldridge \& T. E. Deal (Eds.), Managing change in educational orgunizutions (pp. 151-175). Berkeley, CA: McCutchen.

Baldridge, J. V. (1983). Orgainzational characteristics of colleges and universities. In J. V. Baldridge \& T. E. Deal (Eds.), The dynamics of orgunizutionul change in education (pp. 38-59). Berkeley, CA: McCutchen.

Bennis, W. G. (1976). The sociology of institutions or who sank the yellow submarine? In W. G. Bennis, K. D. Benne, R. Chin, \& K. E. Corey (Eds.), The Planning of Change (pp. 219-227).

Boaz, M. (1982). The use of educational technology: Its influence on higher education. Educational Research Quarterly, 7(3), 2-6.

Botrnan, E. S., \& Gregor, A. D. (1984). Faculty participation in teaching improvement programs. Canadian Journal of Higher Educution, 14(2), 63-73.

Cannon, R. A. (1983). The professional development of Australian university teachers: an act of faith? Higher Education, 12, 19-33.

Carr, J. (1986, Winter). Nonclassroom learning: A review of the literature. In P .S. Breivik (Ed.), Managing programs for learning outside the classroom: New directionsfor higher education no. 56 (pp. 89-96). San Francisco: Jossey-Bass.

Clark, B. R. (1983). The contradictions of change in academic systems. Higher Education, 12(1), 101-116.

Dill, D., \& Friedman, C. (1979). An analysis of frameworks for research on innovation and change in higher education. Review of Educational Research, 49(3), 411-435.

Dowdeswell, W. H., \& Good, H. M. (1982). Academic management - the case for challenge. Canadian Journal of Higher Education, 12(3), 11-24.

Forsythe, K., \& Collins, V. (1983, November) British Columbia-Higher education and the integration of a new technology. Victoria, BC: Knowledge Network.

Habermas, J. (1973). Theory and practice. Boston, MA: Beacon Press.

Hackman, J. D. (1985). Power and centrality in the allocation of resources in colleges and universities. Administrative Science Quarterly, 30(1), 61-77.

Harrington, F. H. (1977). The future of adult education. San Francisco: Jossey-Bass. 
Havelock, R. G., \& Havelock, M. C. (1973). Training for change agents: A guide to the design of training programmes in education and other fields. Ann Arbor, MI: Institute for Social Research, University of Michigan.

Heinich, R. (1984). The proper study of instructional technology. Educational Communication and Technology Journal, 32(2), 67-87.

Holloway, R. E. (1985). Educational technology: A critical perspective. New York: Clearinghouse on Information Resources.

Ikenberry, S. (1972). The organizational dilemma. Journal of Higher Education, 43(1), 23-34.

Jevons, F. (1984). Distance Education in mixed-mode institutions: Working towards parity. Distance Education, 5(1), 24-37.

Kelly, J. T., \& Anandam, K. (1984). Taking advantage of emerging educational technologies. In D. G. Brown (Ed.), Leadership roles of chief academic officers: New directions for higher education no. 47 (pp. 63-75). San Francisco: Jossey-Bass.

Kerr, S. T. (1981). How teachers design their materials: Implications for instructional design. Instructional Science, 10,363-378.

Kozma, R. B. (1985). A grounded theory of instructional innovation in higher education. Journal of Higher Education, 56(3), 300-319.

Lallez, R. (1986). Educational technology in universities in developing countries. Prospects, 16(2), 177-194.

Lane, J-E. (1985). Academic profession in academic organization. Higher Education, 14(3), 241-268.

Liebler, H. (1978). Survey results of ID activity in Higher Education. Journal of Instructional Development, 2(2), 26-31.

Lippitt, R., Watson, J. M., \& Westley, B. (1958). The Dynamics of planned change. New York: Harcourt, Brace and World.

Meyer, J., \& Rowan, B. (1983). The structure of educational organizations. In J. V. Baldridge \& T. E. Deal (Eds.), The dynamics of organizational change in education (pp. 60-87). Berkeley, CA: McCutchen.

Rogers, E. M. (1975). Diffusion of IMPACT innovations to university professors: A final report to the Exxon Education Foundation. Ann Arbor: MI: Department of Journalism, University of Michigan. (ERIC Document Reproduction Service No. ED 116 707).

Rogers, E. M., \& Shoemaker, F. F. (1971). The communication of innovation: A crosscultural approach (2nd ed.). New York: Free Press.

Romiszowski, A. J. (1981). Designing instructional systems: Decision making in course planning and curriculum design. London: Kogan Page.

Rugg, E. A., Warren, T. L., \& Carpenter, E. L. (1981). Faculty orientations toward institutional goals: A broken front with implications for planned change. Research In Higher Education,15(2), 161-173.

Rutherford, D., Fleming, W., \& Mathias, H. (1985). Strategies for change in higher education: Three political models. Higher Education, 14,433-445.

Shrock, S. A. (1985). Faculty perceptions of instructional development and the success/ failure of an instructional development program: A naturalistic study. Educational Communications and Technology Journal, 33(1), 16-25. 
Smith, W. A. S., Daniel, J. S., \& Snowden, B. L. (1984). University distance education in Canada. The Canadian Journal of Higher Education, 14(2). 75-81.

Swanson, E. F. (1983). Four common myths about change in schools of education. Journal of Teacher Education, 34(3), 26-29.

Toombs, W., Lindsay, C., \& Hettinger, G. (1985). Modifying faculty roles to institutionalize continuing professional education. Research in Higher Education, 93-109.

Wartgow, J. F. (1986, Winter). Implementing non-classroom learning: Management considerations. In P. S. Breivik (Ed.), Managing programs for learning outside the classroom: New directions for higher education no. 56 (pp. 7-15). San Francisco: Jossey-Bass.

Williams, H. (1966). Planning for effective resource allocation in universities. Washington: American Council on Education. 


\section{CONCORDIA UNIVER SITY}

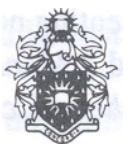

Faculty Positions in

Educational Technology

Concordia University's Graduate Program in Educational Technology invites applications for two tenure track positions. Candidates are expected to have research capability in one of the following areas of priority: computer-aided learning; distance education; intelligent tutoring systems; expert systems in education; interactive video; and evaluation. The successful candidates will teach courses, supervise educational technology internships and direct M.A. and Ph.D. (educational technology) theses. Salary and rank commensurate with qualifications. Applicants should include a curriculum vitae, a brief statement of research objectives, reprints of selected publications and the names of three referees. Documents should be sent to Dr. Richard F. Schmid, Director, Graduate Program in Educational Technology, Department of Education, Concordia University, 1455 de Maisonneuve Blvd. West, Montreal, PQ, Canada H3G 1M8. Deadline: January 31, 1988.

In accordance with Canadian immigration regulations, applications received from Canadian citizens or landed immigrants will be given preference. 


\section{Profile}

\section{Tele-Cottages in the Nordic Countries}

\section{Henning Albrechtsen}

Abstract: The first Scandinavian Information and Community Service Centre (telecottage) was established in Vemdalen, a small village in the middle of rural Sweden, in September 1985. In the tele-cottage local people have access to new information technology on a cooperative basis, thus making them independent of the distance to economic, administrative, educational and cultural centres. The tele-cottage concept has now spread to the rest of Sweden, Scandinavia, and a number of developing countries.

This article outlines the history, functions and organization of Härjedalens Telestuga, the first tele-cottage, and discusses the current and future opportunities afforded by telemttages in remote areas of the world.

\section{INTRODUCTION}

In the small Swedish village of Vemdalen the visitor can witness an unexpected sight. On the first floor of the building containing the local general store a considerable number of modem computers and other equipment are being used diligently by local people from 8 o'clock in the morning until 10 o'clock in the evening. The equipment is worth a closer look: PC AT's(TM), fifteen personal computers from the U.S. and Japan, word processors and teletexts from Holland, Telefax, Videotex, in short, lots of high technology in the heart of a sparsely populated mountainous part of Sweden (Vemdalen today boasts having more computers per capita than any other part of Sweden).

The first Scandinavian tele-cottage, Härjedalens Telestuga, was opened here on September 13, 1985, and shortly after its inception, all this equipment was being used

Henning Albrechtsen is Chairman of the Board of FILIN, Foreningen af Informationsteknologiske Lokalcentre i Norden (Association of Nordic Tele-Cottages) and of IUTC, the International Union of Tele-Cottages. Mr. Albrechtsen will visit Canada in early 1988 and would like to speak to groups and individuals desiring further information about tale-cottages. Those interested should contact him at: Härjedalens Telestuga, Box 54820 92, Vemdalen. SWEDEN. This article is based on two presentations made on separate occasions at the EEC Conference on Social Experiments with Information Technology, Funen, Denmark, January 14-16, 1966, and to the Conference of European Ministers at the inauguration of the Year of the Countryside, Lisbon, Portugal, June 13, 1987. 
by 15 percent of the people in the village, with everyone from 10-year-old children to pensioners represented. The funds for establishing the tele-cottage came from the County Government Board as part of a project for the propagation of modern technology in sparsely populated areas, Swedish Telecom, and the municipal board. The aim of the t\&-cottage was to open up the vast opportunities of the information age to the people in this remote part of Sweden (where there is less than one inhabitant per square kilometre), by providing access to a variety of computers and modern tclecommunications equipment for anyone willing to invest time and energy in learning how to use hardware and software.

Modem information technology has, for the first time in history, given people in remote regions of the earth the opportunity to overcome their worst handicap: their distance from the centres of learning and development. The new information technology may lead to further centralization and to the development of a comparatively small elite, worldwide and in each country. However, if used in the proper way, it may also further decentralization and the development of local democracy. In the Nordic countries, governments arc eager to prevent the cities from growing too large, and the grassroots drive towards local democracy is very strong indeed

\section{THE FIRST TELE-COTTAGE: HÄRJEDALENS TELESTUGA}

The region of Härjedalen is located in the middle of Sweden-a country 2000 kilometres in length -and borders on Norway. It is part of the administrative province of Jämtland which once was a part of Norway and thus belonged to the Danish crown for approximately four hundred years. During the period of violent altercations between Denmark/Norway and Sweden, the Scandinavians became involved in the Thirty Years' War. The Danish king, Kristian IV, had scant success, whereas Protestant Sweden joined forces with Catholic France and triumphed, though the Swedes lost their gallant king. On their way back from the European continent, the victorious Swedish generals conquered Denmark, and as a result of the peace negotiations at the village of Brömsebro in 1645, Denmark was forced to surrender Jämtland/Härjedalen to Sweden.

Even today Härjedalen is a remote part of Sweden. The inhabitants have taken advantage of their mountains and have transformed some villages into skiing resorts, and as Jämtland/Härjedalen is one of the few mountainous regions of Sweden, tourists abound during the high season months of February to April. The region is rich in large forests of pine, fir and spruce, and in the moors peat is found and ensures work for a number of people. However, tourism is stagnating, there is no pulp industry, and the old craftsmen are a dying breed. The young people of Härjedalcn, although loving their beautiful countryside, are often forced to leave their mountain-community to take up work in the industrialized parts of Sweden around the cities of Stockholm, Gothenburg, and Malmö.

The northern parts of Sweden have lost a large number of inhabitants in the last decades. Moving vans, on their way from the sparsely populated areas in the north and west of Sweden towards the southern and eastcrn regions of the country, a frequent 
sight. Swedish governments have for many years tried to halt the stream of people entering the cities, but these efforts have largely been in vain. The County Government Board of Jamtland realized that more efficient measures were needed, and the socialist government of Sweden allocated the sum of 10 million Swedish kronor (CDN \$2 million) to encourage the diffusion of new technology in the province.

The Jämtland County Government Board and the University College of Ostersund, in close cooperation with the Nordic Council of Ministers, arranged a seminar in April 1985 for participants from the Scandinavian countries. The seminar was held at Ostersund, the main town in the province. One of the speakers at the seminar was Mr. Jan Michel from the village of Fjaltring in Denmark. In an inspiring speech he announced his idea of establishing 'tele-huse' in sparsely populated parts of Denmark. His thoughts were eagerly adopted by some Swedish participants and a committee consisting of high-ranking officials of the County Government Board and the University College, in addition to myself, began discussing a Swedish model. The Swedish Televerket, responsible for all telecommunications in the country, saw the considerable potential of the idea and its local director joined the committee. Subsequently, a decision was made to start up 'Härjedalens Telestuga', the Electronic Village Hall of Härjedalen, as soon as possible. A document, adopting many ideas from the Danes, established the aims of the tele-cottage (as it is now called) as follows:

1) to give the local population the chance of using modem technological equipment, thus removing their fear of the computer and their resistance to it;

2) to help local tradespeople in purchasing the right kind of equipment, suited to their needs;

3) to educate a large number of people in the use of modem computers, thus making them independent of the distance to the cultural centres and facilitating their access to the information age;

4) to further local democracy; and

5) to increase international cooperation.

Local politicians in the community were quite skeptical about the project in its first phases. The committee had drawn up a budget of SEK 700,000 (CDN \$150,000) for the first six months, but the local officials showed no inclination to contribute. As the local papers, the local radio, and local entrepreneurs praised the project, however, the mayor and his colleagues had second thoughts. The budget was extended to one million Swedish kronor (CDN \$200,000), and the community council voted unanimously to contribute 400,000 SEK (CDN \$85,000) to the Telestugan. In the end, the local politicians chose not to leave all initiative to the County Government Board, and to the Televerket which provided 300,000 SEK (CDN \$65,000), primarily in the form of equipment (Teletex, Telefax, Videotex, and some personal computers).

From the very start, the idea of the tele-cottage has met with considerable interest inside and outside Sweden, and when the Telestugan was officially opened in September 1985, we were happy to receive delegations from Denmark, USA, Norway, Italy, France and the UK among our guests. A delegation from the OECD attended, including former British Cabinet Minister Mrs. Shirley Williams, MP, and the EEC's Mr. Lars 
Qvortrup. A seminar was held and the Härjedalen papers wrote considerably on the opening. It is estimated that more than $50 \%$ of the local population attended the official opening of the Telestugan by Professor Inez Sperr Brisfjord of Long Island University.

No idea is right unless it appears at the right moment, says Alvin Toffler. The idea of the Tclc-Cottage was indeed introduced to the people of Härjedalen at the right moment. A civil servant from a neighboring village expressed the general feeling in the following terms: "Some ten or fifteen years ago I heard a tiny noise behind me; the computer was said to be of importance for everybody in the future. Today I have the feeling that the noise has increased and has overtaken me. I risk being left behind if I do not catch the train in the very last moment".

Härjedalens Telestuga has created new life and a spirit of optimism in the region of Härjedalen, and the idea of Jan Michel has spread. Since its opening, several study groups from other parts of Sweden have visited each month, and many of these groups have told us that they returned to their home to create their own tele-cottage. In the province of Jämtland, for example, two new tele-cottages were started in November and December 1985. Norwegian Television spent a day in the Telestugan filming the activities and interviewing a number of people, and the resulting programme was shown on Norsk Rikskringskasting on a Sunday evening in December 1985. The very next day, a group of people from a village outside Bergen telephoned to establish contact, and a new Norwegian Telestugan project was on its way. A Danish project also was initiated around that time. The tele-cottage seems to have marked the beginning of a new spirit of optimism and entrepreneurship on our old continent. It is my considered opinion that there ought to be many tele-cottages all over Europe if we are to maintain our independence vis-a-vis the superpowers in the information era.

\section{CURRENT FUNCTIONS OF THE TELE-COTTAGE}

\section{Infoteque}

A tele-cottage is organized to offer courses in the handling of modern computers and telecommunications cquipmcnt, teach people how to search for relevant information in national and international databases, and provide access to computer-aided learning materials and to a wide range of hardware and software. Such an 'infoteque' could combine the functions of the local library, the school library, the tele-shop, the post office, and the communications centre. (In many small villages the population is so small that the costs of providing library and public mail services are almost prohibitive) .

In the first tele-cottage, over $20 \%$ of the local inhabitants have taken one or several courses, and the participants have come from all walks of life; small scale entrepreneurs and/or their spouses, shop assistants, farmers, craftspeople, and children. We started having 'Open House' on Friday afternoons for the children, in the hope that after having tried a number of computer games for some months, they would express a desire to learn more substantial information. They started asking for courses after six weeks, and when we gave the pupils in the 4th, 5th, and 6th forms of the village school the offer of two lessons a week, 16 out of a total of 21 children joined the course. When 
their older brothers and sisters heard about it, we were forced to start courses for them as well.

The aim of the present general education at the tele-cottage is to create a demand for specialized courses in bookkeeping, planning, calculations, word processing, communications, computer-aided design, and many other subjects.

The tele-cottage in Vemdalen is equipped with a combined television/videotex set. A rather large room has been cosily furnished with locally manufactured furniture and a large TV set. In this room all villagers are welcome to watch TV programs received from satellites (with programs in English, German, and French, and plans for reception of still more satellite signals). Between television programs, Videotex provides relevant information on subjects of local interest: the agenda from the last meeting of the community council, information from the County Government Board, information on vacant positions in the district, and so on. Many small villages today have no natural meeting place for the villagers. Pubs, for example, are rare in rural Sweden. In the village of Vemdalen, the drawing room of Telestugan is being used every day by a considerable number of people.

Another advantage for the locals in having the Telestugan so near is the fact that they are welcome to use the computers in a separate room, either for training - many people drop in when they have finished shopping in the grocery store, while others use their lunch break for reviewing the previous night's lessons - or for doing their bookkeeping. In the drawing room they find technological papers and magazines, and people with whom they can discuss the implications of the information age for their community and for themselves. During these discussions many new ideas are launched, some of them to disappear again, others to be translated into real-life undertakings.

The tele-cottages should be run by local people. They constitute a grassroots movement, possibly the missing link between little populated, remote areas of the world and the centres of information. If the cottages are indeed to be this 'missing link' in developing countries, for instance, it must be clearly shown elsewhere that the new technology can be adapted to the users and their needs, and not vice versa. It is very important that the new technology, as used in the tele-cottages, is accepted by the population of the Northern European countries as part of their own cultural heritage. In this, the tele-cottages have been seen to work dynamically in sparsely populated areas. In a village where barely two years ago people in general did not dare touch a computer, using the modem equipment is now the most natural thing in the world.

\section{Employment Creation and Service to Small-Scale Enterprise}

The Telestugan employed five persons shortly after its opening, and this number has increased recently. From the beginning it was decided to establish, in connection with the Telestugan, a number of jobs where people could sit at home, each working with their own computer connected to the main computer in the tele-cottage. This kind of work was initially viewed with distrust by the unions if it meant that individuals were to be doing some kind of low-paid homework for large corporations, as such workers are easily exploited in their isolation. The trade unions have followed the Vemdalen project closely and have now given their consent to placing distance-work from the cities in the tele-cottages, as the employees are ensured their rights and social 
contacts. In the framework of the Telestugan they are also ensured just wages, and they will be members of the Telestugan staff. They can work at home if they prefer to do so, for a shorter or longer term, but they can also join their colleagues in the tele-cottage if they feel so inclined. The climate in the tele-cottages is warm and supportive. In any case, the Telestugan maintains close cooperation with the trade unions, one of which, the TCO, has formally signed an agreement on joint education with Härjedalens Telestuga.

The Telestugan also offers service to small and large enterprises in the region. Letters, offers, drawings and other documents are sent by Telefax after instructions are given by phone. The Telestugan provides help in translating offers and letters into a number of foreign languages, and the documents reach the addressees in a few seconds by Telex. Smaller enterprises can in this way benefit from the new technology without having to invest in costly equipment, and many firms, clubs and associations already use the services of Härjedalens Telestuga. The tele-cottage even functions as an office for certain small enterprises and, not being in the pay of any computer manufacturer, also offers fair and balanced advice on the purchase of hardware and software, while providing support to those who have bought computers and software. The service to small-scale enterprise has been much used and greatly appreciated, and has attracted several export orders to the region. The School of Administration and other departments of the Swedish Army are using the tele-cottage as a supplementary office. Distance is now not measured in miles, but in minutes and seconds; however, many large firms have still not realized the possibilities of sending work in peak periods to the tele-cottages.

The initial investment in the Telestugan was one million Swedish kronor (CDN $\$ 200,000)$. It was from the onset expected that the project should receive more funds in the beginning of 1986. From the first day, however, Telestugan was entrusted with the task of preparing computer/plotter programs for a large project aimed at utilizing some of the numerous moors of Härjedalen for the production of peat. By referendum it has been decided that the nuclear plants of Sweden shall be closed down by 2010, and the hunt for domestic fuel has already begun. As a result of the work on the peat project carried out in the Telestugan, a new task has been given to us. The aid organization of the Swedish government, SIDA, launched a well-analyzing project in India, and the computer programs for this project are being run in the village of Vemdalen. Our world has really become smaller in this day and age! These two projects plus the educational activities - 90 lessons a week and the service to local firms have ensured us a monthly income of approximately SEK 150,000 (CDN \$30.000). There is good reason to believe that further grants will not be needed.

\section{A Network of Competence}

Supported with funds from the Nordic Council of Ministers, a database is being established to unite the Scandinavian tele-cottages. If the sparsely populated parts of Scandinavian countries are to compete with the sophisticated data centres in the large cities, work which originates there must be of the same high quality. If competition on equal terms cannot be achieved, the remote areas will be forced to accept secondary jobs with less remuneration, and the well-known vicious circle will have started once 
again. FILIN - Foreningen af Informationsteknologiske Lokalcentre i Norden, the Association of Nordic T\&-Cottages- will operate this database and is also trying to open marketing offices in all capitals and larger cities of Scandinavia. These offices are intended to act as part of the FILIN network as well, to see that work which is available is sent to the countryside. FILIN has today around 30 full members in Denmark, Norway, Finland and Sweden. In Sweden 35 to 50 new tele-cottages are under preparation, and the Norwegian government and Norsk Data are supporting efforts at creating local telematics centres in that nation's countryside. The next FILIN conference is taking place in September 1987 in Thorshavn, the largest city in the Fame Islands in the North Atlantic, and plans for a conference and a seminar in Iceland in early spring are under way.

\section{THE FUTURE OF THE TELE-COTTAGE}

The developing world has followed the Nordic experiments closely and with considerable interest. Plans are being made to establish t\&-cottages in Papua, New Guinea, Sri Lanka, India, Indonesia, Benin and Nigeria, and in several countries in South America. The International Telecommunications Union (ITU) in Geneva and other international organizations are following the developments continuously, and an international association is being formed. The first general assembly will take place in Geneva shortly.

The government of Sweden has declared the establishment of tele-cottages a top priority in the on-going campaign for the rural areas. At the exhibition at Santarem, Portugal, arranged by the Council of Europe, the Swedish tele-cottage was received with considerable interest, and meetings have been held with representatives from the Greek and the Portuguese Telecom for the purpose of setting up tele-cottages in the rural areas of these countries.

The Council of Europe has adopted the tele-cottage as one of the main themes in the campaign for the countryside, and the idea will be followed up in seminars and conferences all over in the coming 18 months. FILIN is negotiating with many individuals, authorities, computer firms and other interested parties all over the world. The year of the countryside could easily become the year of the European tele-cottage. "Vivons nos campagnes" is the French slogan for the campaign. The tele-cottages contribute to making the countryside more than a place for recreation and a museum for showing how ancestors lived. Through them, we can give the countryside the most important thing of all-a living present and a promising future. 


\section{From the Educational Communication and Technology Periodicals \\ Richard Ellis, Editor}

This column is an edited listing of articles that have appeared recently in the

literature of educational communication and technology.

British Journal of Educational Technology, 18 (2), January 1987.

Gudgin, A. N. "Computer-assisted learning of introductory economics"

Adams, D. M., \& Hamm, M. "'LogoWriter'. Stretching the boundaries of educational computing: A review"

Menis, J. "Teaching by computers: What the teacher thinks about it; and some other reflections"

Chandra P. "How do teachers view their teaching and the use of teaching resources?"

Melton, R. F., \& Zimmer, R.S. "Multi-perspectivc illumination"

Barker, P. "A practical introduction to authoring for computer assisted instruction. Pan 9: Database support"

Barker, P., \& Proud, A. "A practical introduction to authoring for computer assisted instruction. Part 10: Knowledge-based CAL"

Classroom Computer Learning, $7(8)$, May 1987.

Gandy, T. J. "The inservice workshop: When you're responsible for introducing other teachers to the mysteries of micros"

Eiser, L. "Print it! 101 things to print with your computer"

Vlahakis, R. "The other side: Snapshot of a social studies simulation in action"

Brooks, S. "Toy store robots"

Computers in Education, 4(9), May 1987

Gleadow, N. "School-wide computer literacy"

Walpole, P. O. "Computers, wheelchairs and one reality"

Cathcart, W. G. "Using the ASCII code"

Nicklin, R. C. "The celsius computer: Part II"

Humphreys, D. "Information and databases"

Eiser, L. "Typing programs"

Richard Ellis is with the D. S. Woods Education Library at the University of Manitoba, Winnipeg. MB. 
Computers in Education, 4 (10), June 1987.

Lee, I. A. "Teaching in a microcomputer lab"

Wong, E. "Computers in music education"

Caissy, G. A. "Using databases in the classroom"

Maher, P. "Printing programs"

Cathcart, W. G. "Secret codes: An advanced version"

Educational Technology, $27(8)$, August 1987.

Sims, H. A. "Desktop publishing in a PC-based environment"

Devan, S. "Desktop publishing on the Macintosh: A software perspective"

Eastman, S. "Workstation publishing"

Winkel, B. J. "TEX: Is this artistic technical typesetting for you?"

Lucking, R. "Shoestring publishing: Inexpensive alternatives in desktop publishing"

Hamilton, W. "Desktop publishing for the gifted/talented"

Little, D., \& Suhor, C. 'School uses of desktop publishing: Asking the right questions"

Educational Technology, 27(7), July 1987.

Hosie, P. "Adopting interactive videodisc technology for education"

Goldberg, A. L. "Educational technology: A regional perspective"

Gallegos, A. M. "Technology in the classroom: Another look"

Suzuki, K. "A short-cycle approach to CA1 development: Three-stage authoring for practitioners"

Hoko, J. A. "The quality of error: Toward updating the learning curve"

Smith, C. L. "Educators as courseware developers: The key to successful microtechnology integration"

Davidore, E. A. "Evaluation and selection of courseware development software"

Wright, C., Zwicker, D., \& Conroy, C. "Share tech: Nurturing technological change in your institution"

Journal of Computer-Based Instruction, 14 (2), Spring 1987.

Trollip, S. R., \& Lippert, R. C. "Constructing knowledge bases: A promising in structional tool"

Wood, L. E., \& Stewart, P. W. "Improvement of practical reasoning skills with a computer game"

Gray, S. H. "The effect of sequence control on computer assisted learning"

Fish, M. C., \&Feldmann", S. C. "A comparison of reading comprehension "sing print and microcomputer presentation"

Sizemore, M. H., \& Pontious, S. "CAI promotes nursing student mastery of history taking" 
Madsen, J. M., \& Sebastiani, L. A. "The effect of computer literacy instruction on teachers' knowledge of and attitudes toward microcomputers"

Dalgish, G. M. "Utilizing randomization and open-endedness in ESL software"

Journal of Educational Technology Systems. 15(4), 1986-87

Derry, S. J., Jacobs, J., \& Murphy, D. A. “The JSEP lcaming skills training system"

Yamamoto, Y., \& Vanin, 0. G., Jr. "CA1 systems in English"

Hocking, R. T. "The evolution of CA1 in an advanced finance course"

Roderick, J. C., \& Forcht, K. A. "The merging of computers and business communications"

Sharma, S. 'Learners' cognitivc styles and psychological types as intervening variables influencing performance in computer science courses"

McCaughey, M. P. "Synchronizing a tape recorder to an educational computer program"

Stem, C. M. "Teaching the distance learner using new technology"

Media \& Methods, 23(5), May/June 1987

Larsen, R. A. "Interactive video: Designing your own"

Richardson, J. H. "Capitalizing on the big 


\title{
Book Reviews
}

\section{Rose Bene, Editor}

\author{
The book reviewed in this issue is: L'école devant les écrans (The School in Front \\ of the Screens) by Geneviève Jacquinot.
}

L'école devant les écrans by Geneviève Jacquinot. Les Editions E S F, Paris, France, 1985. in French.

\section{Reviewed by Pierre Bélanger}

In the spring of 1987, Montréal's French daily La Presse began publishing a full page of assorted information every Friday intended for elementary school students. The objective of this venture was to bring to the classroom a fragment of the current events which make the world what it is. Adapted texts corresponding to the pupils' intellectual level allow them to begin to make sense of what goes on around them in a critical and analytical manner. This is official recognition, of sorts, that the school is not a closed-in milieu, but that it can integrate and learn from some of the information materials destined for the public-at-large,

Dr. Jacquinot's book L'école devant les écrans (The School in Front of the Screens) extends this thinking to consider some of the most urgent questions affecting today's educational system. Are the new technologies really innovative with regard to the way in which the school handles formal teaching situations? How are we to maximize the educational potency of TV, cinema, radio, and the computer within an integrated education? In addition to exposing the philosophical, social, cultural, and pragmatic aspects of opening up the school to audiovisual (AV) sources of information, the author discusses the findings of research studies in which she has participated in France and other international settings. Dr. Jacquinot contends that, owing to the proliferation of new technologies, mediated images and sounds have now become ubiquitous, and their informative and educational potentials must be assessed and taken seriously. Yet the paucity of both the research into the teaching functions of audiovisual media and the researchers who conduct them leads one to conclude that print is still given priority over other media. In so doing, one perpetuates a form of learning that could certainly benefit from a trend towards less formal, less individualistic ways of acquiring knowledge. It is not that Dr. Jacquinot intends to remodel the education system altogether. Unlike many technological prophets, she does not wish to replace textbooks by computer screens, or chalk by joysticks. Adopting a more temperate stance, she believes that a rational examination of the audiovisual production and 
diffusion of various types of messages could contribute significantly to a better understanding of the mechanisms at play in the acquisition of knowledge.

In this vein, she denies the behavioristic stance of stimulus-response research, and instead proposes a dialectical conception of media effects in which social interaction has a major impact on what is retained from a message, program, film, etc. This insistence on the vital role of social interaction in lcarning leads to an examination of the epistemological differences between learning from computers and learning from a teacher. The current claim by technology designers and manufacturers that many of their products allow the user to interact with the machine and to personalize lcarning is seriously questioned by Jacquinot. She contends that one must first qualify this interactivity and determine its extent. How does working with a computer differ from learning in a class setting where, as a rule, only question-answer interactions are allowed? This query is indicative of the direction the author takes in her book. Primarily known as an educational semiologist, Dr. Jacquinot applies a heuristic perspective to her research.

In the first chapter, the author makes the surprising contention that semiology, as it is now known and practiced, is passe. She alleges that the traditional approach to the study of signs is far too limiting and fails to account fully for the highly subjective context of surrounding message reception. An integration of the study of rules underly ing the formation of a message, as well as the locations and conditions of their production and propagation into semiology, would extend it.s limits by including the 'social operativity' of a message, a factor about which Dr. Jacquinot is most adamant. Another concept in this first section is that of 'iconic compctcnce', whereby students are given the opportunity to become skilled at 'reading' the significance of visuals and ultimately at utilizing them (in anglophone writing this notion is commonly referred to as 'media literacy'). Borrowing from cognitive psychology, Jacquinot indicates the need to identify those properties inherent in sounds and images which can be applied in designing a model of instruction specifying the interrelationships between the audiovisual elements (intertextuality). To the reader of the English literature, of course, such ideas are already familiar from the writings of Gabriel Salomon, Erhard Heidt, Jon Baggaley and others, all of whom were first introduced to France by Dr. Jacquinot in Communications (No. 33, 1981). In this area of educational media literature, it appears that the English-French language barrier may have created two academic 'solitudes', with Geneviève Jacquinot as its prime French proponent. Dr. Jacquinot communicates her ideas with scholarly originality, and one cannot help but wonder at the impact her research would have had on the North American readership if the theoretical ideas of both languages had been fully integrated.

A point most worthy of investigation in Dr. Jacquinot's writing is her opinion regarding the blatant under-utilization of commercial TV programming in today's school system. Contrary to popular belief, TV is not a homogenizing activity, but one among many sources which accentuate socio-cultural differences. Hence, Jacquinot contends, it is the school's duty to show students the components of the cultural environment in which they live. This is a difficult objective in that it calls for a multidisciplinary approach to teaching, one that dwells on images and sounds as the very objects of learning. Jacquinot perceives a dual benefit in exploiting the 'polysemantics' 
of the TV image encouraging the students to express and share the types of relationships they observe among the elements of a TV program will not only open their minds to the ways other people interpret the same situation, but will also actively enrich their linguistic development. Any instructional model which allows the student to sift through the maze of information available to him in this way deserves a thorough and exhaustive examination. Too often, writes Jacquinot, technological innovations in education have more to do with economics than pedagogy. This is a sensitive area if there ever was one, upon which the inadequacy of teacher training has a direct baring.

To the North-American reader unfamiliar with Dr. Jacquinot's experiments at Marly-le-Roi (France), and on the Ivory Coast, concerning the incorporation of AV practices into the school, chapters 2 and 3 of the book may appear too distant to have any bearing on the North American experience. However, Dr. Jacquinot makes an earnest effort to decontextualize the emergence of educational TV and cinema on the Ivory Coast, in order to draw some general conclusions regarding the impact that AV technologies have had on that mainly rural country. One can compare the author's account to those of Edmund Carpenter (Oh, What A Blow That Phantom Gave Me!) who tested aboriginal peoples' reactions to media and the ensuing reciprocal influences between them. On the Ivory Coast, just as anywhere else where TV operates, the villagers are reported to have developed a more visible feeling of 'appartenance' to their community since the medium's introduction. The parallel with the current development of broadcasting activities by Canada's Inuit population is striking.

Although scientifically more rigorous and socially closer to home, the educational experiments at Marly-le-Roi cast a grim light on the extent to which technology has managed to improve educational standards. The project was initiated in 1968 as an ideal opportunity to demonstrate that AV education does not always need to reinforce authoritarian models of instruction, and that educational technology does not automatically imply a technicist conception of leaning. However, thirteen years of creative, dynamic research ended up gathered in a final summative report which, like many of its kind, has not yet instigated any firm action in either direction. What was once conceived as tbe state of tbe art in educational research has only had minor repercussions in practice. Given a favourable economic and political climate, many of the Marly findings could be applied in schools today, easing the nervousness and insecurity which many educators exhibit vis-a-vis the new technology.

The educational prospects of television are given substantial attention in chapter 4 . While comparing tbe dismal status of France to the impressive one of Great Britain with regards to educational TV/radio production, Dr. Jacquinot deplores the general inability of scholars to generate leaning models more in line with the possibilities afforded by audiovisual technological developments. The author is a strong advocate of authentic AV documents which students and teachers can use to construct 'social signifiers'. Of vital importance in one's cognitive development is the freedom given to the individual in the modalities of appropriating knowledge. Hence the necessity of using high-quality TV documents (so tbat they be culturally, socially and historically meaningful to the students) and of providing high-quality educational practices related to them.

By the last third of the book, it becomes increasingly clear that for Dr. Jacquinot 
the term 'interactivity' is not strictly an aspect of instructional technology but rather a bona fide element of education in and of itself. Stretching a somewhat restrictive definition of the term, the author suggests that 'educational interactivity' be used to designate the kinds of interaction that evolve when one concentrates on the student as the core of the learning process. Assisting the student to interact meaningfully with his environment is meant to facilitate the creation of links, contacts and bridges of semantic relevance with it. Dr. Jacquinot wisely warns us of the consequences of a blind faith in modem educational technology. The latter is capable of replacing a number of traditionally redundant tasks, but nevertheless demands of the teacher a deeper knowledge and mastery of the processes involved in learning. The onus is on the best way in which to reach the educational objectives desirable for the majority of the students.

For anyone hesitant about the rationale for opening up the school to technologically-mediated sources of information and knowledge, Dr. Jacquinot's book represents a strong collection of arguments in favour of it. She uses a graphic analogy to epitomize her thesis: parks educate and museums divert people. As for those doubting the leaner's ability to ingest and store the glut of images disseminated by information technology, Dr. Jacquinot offers this advice: allow the students to bring to class those experiences and knowledge they have acquired outside of it. With the help of teachers and schoolmates, pupils are thus given a chance to put some order in the mass of information they are exposed to through the communication networks as well as encouraged to react more critically and discriminatingly to them. In the final analysis, we all stand to gain if the school admits into its domain the multi-screen perspective afforded by the media. If Dr. Jacquinot's reasoning manages to instigate sufficient debate in educational milieus, the day may be near where parents will begin asking their children "Did you have an entertaining schoolday?". One may already observe timid manifestations of this concept surfacing in social studies and language classes. For future research the question then becomes: How entertaining can learning get before it reaches an unproductive plateau?

Pierre Bélanger is a doctoral student in the Graduate Programme in Educational
Technology at Concordia University.




\section{Index to Volume 16, 1987}

\section{Articles (by title)}

Communication technology in higher education in Alberta: Current Status and policy perspectives, D. G. Crawford and Gail C. Crawford, 16(3), 205-216.

Continual response measurement: Design and validation, Jon Baggaley, 16(3), 217-238.

Developing interactive videotape in a university setting, Michael Palmer and Mariela Tovar, 16(3), 195-204.

An edited transcript of CoSy 'bcjec', Robert M. Bernard, Jacques LeCavalier and Don Beckwith (Eds.), 16(2), 173-191.

Educational applications of computer conferencing, Elaine K. McCreary and Judith Van Duren, 16(2), 107-115.

Emancipative educational technology, Gary M. Boyd, 16(2), 167-172.

Evaluating educational software authoring environments using a model based on software engineering and instructional design principles, Betty A. Collis and Marilyn Gore, 16(1), 11-22.

An extension of PSI through the application of instructional systems design technology, Dan O. Coldeway and Annabel E. Coldeway, 16(4), 279-293.

Facilitating 'extended campus' graduate education through electronic communication, T. Craig Montgomerie, 16(3), 239-256.

The formative evaluation of a university videotext system, Richard T. Hezel and Karen R. Miller, 16(1), 23.32.

Group problem solving via computer conferencing: The realizable potential, Don Beckwith, 16(2), 89-106.

How costly are computer-based instructional systems? A look at two approaches, George A. B. Moore, 16(1), 33-44.

The importance of involving experts and learners in formative evaluation, Cynthia B. Weston, 16(1), 45-58.

The integration of educational technology in the university, Diana R. Carl, 16(4), 309-325.

Introducing computer-mediated communication into a distance education system, Tony Kaye, 16(2), 153-166.

Introduction to the special issue on computer-mediated communication, Robert $\mathrm{M}$. Bernard and Steven Shaw, 16(2), 87-88.

Resistance to planned change: A training design case study, Lynn McAlpine, 16(3), 257-264.

The status of media centres in Canadian universities, Esio Marzotto, 16(1), 59-64. Teaching and learning on-line: Issues in computer-mediated graduate courses, Linda Hamsim, 16(2) 117-135. 
T\&-cottages of the Nordic countries, Henning Albrechtsen, 16(4), 327-233.

Theoretical bases for research in media, Gerald M. Torkelson, 16(1), 3-10.

Towards a third generation distributed conferring system, Roger Hart, 16(2), 137-152.

The value of supplementing panel software reviews with field observations. Ronald D. Owston and Herbert H. Wideman, 16(4), 295-308.

\section{Articles (by author)}

Albrechtsen, Henning. T\&-cottages of the Nordic countries, 16(4), 327-233.

Baggaley, Jon. Continual response measurement: Design and validation, 16(3), 217-238.

Beckwith, Don. Group problem-solving via computer conferencing: The realizable potential, 16(2), 89-106.

Beckwith, Don (Ed.). See Bernard, Robert M.

Bernard, Robert M. and Steven Shaw. Introduction to the special issue on computermediated communication, 16(2), 87-88.

Bernard, Robert M., Jacques LeCavalier and Don Beckwith (Eds.). An edited transcript of CoSy 'bcjec', 16(2), 173-191.

Boyd, Gary M. Emancipative educational technology, 16(2), 167-172.

Carl, Diana R. The integration of educational technology in the university, 16(4), 309-325.

Coldeway, Annabel E. See Dan O. Coldeway.

Coldeway, Dan 0 and Annabel E. Coldeway. An extension of PSI through the application of instructional systems design technology, 16(4), 279.293.

Collis, Betty A. and Gore, Marilyn. Evaluating educational software authoring environments using a model based on software engineering and instructional design principles, 16(1), 1 1-22.

Crawford, D. G. and Crawford, Gail C. Communications technology in higher education in Alberta: Current status and policy perspectives, 16(3), 205-216.

Crawford, Gail C. See Crawford, D. G.

Gore, Marilyn. See Collis, Betty A.

Harasim, Linda. Teaching and learning on-line: Issues in computer-mediated graduate courses, 16(2), 117-135.

Hart, Roger. Towards a third generation distributed conferring system, 16(2), $137-152$.

Hezel, Richard T. and Miller, Karen R. The formative evaluation of a university videotext system, 16(1), 23-32.

Kaye, Tony. Introducing computer-mediated communication into a distance education system, 16(2), 153-166.

LeCavalier, Jacques (Ed.), See Bernard, Robert M.

Marzotto, Esio. The status of media centres in Canadian universities, 16(1), 59-64.

McAlpine, Lynn. Resistence to planned change: A training design case study, 16(3), 257-264. 
McCreary, Elaine, K. and Van Duren, Judith. Educational applications of computer conferencing, 16(2), 107-1 15.

Miller, Karen R. SeeHezel, Richard T.

Montgomerie, T. Craig. Facilitating 'extended campus' graduate education through electronic communication, 16(3), 239-256.

Moore, George A. B. How costly are computer-based instructional systems? A look at two approaches, 16(1), 33-44.

Owston, Ronald, D. and Wideman, Herbert H. The value of supplementing panel software reviews with field observations, 16(4), 295-308.

Palmer, Michael and Tovar, Mariela. Developing interactive videotape in a university setting, 16(3), 195-204.

Shaw, Steven. See Bernard, Robert M.

Torkelson, Gerald M. Theoretical bases for research in media, 26(1), 3-10.

Tovar, Mariela. See Michael Palmer.

Van Duren, Judith. See McCreary, Elaine K.

Weston, Cynthia B. The importance of involving experts and learners in formative evaluation, 16(1), 45-58.

Wideman, Herbert H. See Owston, Ronald D

\section{Columns (by title)}

From the Educational Communication and Technology Literature, Richard Ellis (Editor), 16(1), 71-74; 16(3), 267-270; 16(4), 334-333.

Media Managers, Marvin E. Duncan (Author), Developing a survival strategy: Supporting a college or university learning resources center, 16(1), 65-68.

Mediography, Nancy L. Lane (Editor), Topic: Media for Special Education, 16(1), 75-77.

Microware Review, Len Proctor (Editor), The sider hard disk and the Apple IIe by Ron Berntson, 16(1), 69-71;

Microware Review, Len Proctor (Author), Keyboarding primer and MECC keyboarding master, 16(3), 265-266.

\section{Columns (by author or editor)}

Berntson, Ron (Author). Microware Review, The sider hard disk and the Apple IIe, 16(1), 69-71.

Duncan, Marvin E. (Author). Media Managers, Developing a survival strategy:

Supporting a college or university learning resource center, 16(1), 65.68.

Ellis, Richard (Editor). From the Educational Communication and Technology

Periodicals, 16(1), 71-74; 16(3), 267-270; 16(4), 334-336.

Lane, Nancy L. (Editor). Mediography, Topic: Media for Special Education, 75-77. 
Proctor, Len (Editor). Microware Review, The sider hard disk and the Apple IIe by Ron Berntson, 16(1), 69-71.

\section{Book Reviews (by title)}

L'ecole devant les ecrans (The School in Front of the Screens) (1985) by Genevieve Jacquinot. Reviewed by Pierre Belanger, 16(4), 337-340.

Practical guide to computers in education, 2nd ed. (1985) by Peter Coburn, Peter Kelman, Nancy Roberts, Thomas F. F. Snyder, Daniel H. Watt and Cheryl Weiner. Reviewed by Arnold Keller, 16(1), 83-84.

Television production handbook, 4th ed. (1984) by Herbert Zettl. Reviewed by Rose Bene, 16(1), 79-83.

Transmission (1985) by Peter D’Agostino (Editor). Reviewed by Suzanne Daningburg, 16(3), 271-272.

Using computers: Human factors in information systems (1986) by Raymond $S$. Nickerson. Reviewed by J. T. Giard, 16(3), 273-275.

\section{Book Reviewers}

Belanger, Pierre. L'ecole devant les ecrans (The School in Front of the Screens). (1985) 16(4), 337-340.

Bene, Rose. Television production handbook. 4th ed. (1984), 16(1), 79-83.

Daningburg, Suzanne. Transmission (1985), 16(3), 273-275.

Giard, J. T. Using computers: Human factors in information systems (1986), 16(3). 273-275.

Keller, Arnold. Practical guide to computers in education, 2nd ed. (1985), 16(1), 


\section{Information for Authors}

General Policies
CJEC welcomes papers on all aspects of educational communication and technology. Topics include, but are not limited to: media and computer applications in education, learning resource centers, communication and instructional theory instructional design, simulation, gaming and other aspects of the use of technology in the learning process. These may take the form of reviews of literature, descriptions of approaches or procedures, descriptions of new applications, theoretical discussions and reports of research.

\section{Manuscript categories}

Manuscripts may fall into one of two classes: General, dealing with a topic or issue at a general level (although reference to specific instances or examples may be included). and Profiles, dealing with or describing only a specific instance of an approach, technique. program, project, etc. A Profile may be thought of as a descriptive case study.

Most manuscripts dealing with a topic in general should include reference to supportive literature, while manuscripts submitted to the Profile category may or may not. The Editor reserves the right to change the designation of a manuscript or to make a designation, if none has been made previously by the author. Authors interested in determining the suitability of materials should consult past issues of CJEC or contact the Editor.

All manuscripts received by the Editor (either general or profile) will be judged for suitability, contribution, accuracy, etc. by a panel of anonymous reviewers designated at the time of submission. Normally, the review process requires about eight weeks. There are no deadlines for the submission of manuscripts.

\section{Manuscript Preparation}

Manuscripts should be typed on $81 / 2 \times 11$-inch ordinary white paper. All materials must be double-spaced, including quotations and references. Include a title page on which appears the title of the manuscript, the full name of the author(s) along with position and institutional affiliation, mailing address and telephone number of the contact author. An abstract of 75-150 words should be placed on a separate sheet following the title page. While the title should appear at the top of the first manuscript page, no reference to the author(s) should appear there or any other place in the manuscript. Elements of style, including headings, tables, figures and references should be prepared according to the Publication Manual of the American Psychological Association, 3rd Edition, 1983. Figures must be camera-ready.

\section{Submission of Manuscripts}

Send fourcopies of the manuscript to the Editor along with a letter stating that the manuscript is original material that has not been published and is not currently being considered for publication elsewhere. If the manuscript contains copyright materials, the author should note this in the cover letter and indicate when letters of permission will be forwarded to the Editor. Manuscripts and editorial correspondence should be sent to: Robert M. Bernard, Canadian Journal of Educational Communication, Education Department, Concordia University, 1455de Maisonneuve Blvd. W., Montreal, PQ, H3G 1 M8. 